\title{
Las estructuras sociales de endeudamiento y los grupos de referencia comunitarios. Una comparación internacional
}

\author{
Roberto Herranz-González \\ Universidad de Santiago de Compostela. Departamento de Sociología \\ roberto.herranz@usc.es
}

\section{Carlos P. del Oro-Sáez}

Universidad de Santiago de Compostela. Departamento de Economía Cuantitativa carlospio.deloro@usc.es

\section{Resumen}

Aunque la sociología económica se ha interesado por la sociología de la deuda y del crédito, ha prestado poca atención a una definición sistemática de las estructuras sociales de endeudamiento y al papel que desempeñan en el contexto de los procesos de desarrollo económico. En el presente trabajo, se comienza discutiendo este concepto observando, a la luz de la evidencia empírica, las diversas formas que pueden adoptar estas estructuras. A partir de los datos recogidos por la encuesta ISSP 2001 realizada en 26 países, se profundiza en el estudio de los tipos de relación social de endeudamiento en función de los grupos de referencia (familiares, extrafamiliares, bancarias) a los que los entrevistados dicen que acudirían en caso de que necesitasen una gran cantidad de dinero. Se estudian las orientaciones y los grupos de referencia de cada país en función de su nivel de desarrollo. Los resultados del análisis revelan la presencia de importantes contrastes entre estados con niveles de desarrollo muy diferentes y permiten descubrir pautas que muestran la presencia de espacios formales o informales de endeudamiento. La diversidad en la composición de los grupos de referencia refleja la variedad existente en las estructuras sociales de endeudamiento.

Palabras clave: sociología económica; deuda; redes sociales; préstamos; sociología del crédito 
Abstract. Social Structures of Debt and Communitarian Reference Groups: An International Comparison

Although economic sociology has been interested in the sociology of debt and credit, it has paid less attention to a systematic definition of the social structures of debt and the role they play in the context of economic development processes. This paper begins by discussing this concept through observing the various forms that these structures can take. Based on data from the ISSP 2001 survey conducted in 26 countries, social relations of indebtedness are analyzed in terms of the reference groups (family positions, outside the family, banking) that respondents would turn to if they needed a large amount of money. The orientations and reference groups adopted in each country are studied according to their level of development. The results of the analysis show the presence of important contrasts between countries with very different levels of development and reveal patterns that indicate the presence of formal and informal spaces of indebtedness. The diverse composition of the reference groups reflects the variety of social structures of indebtedness.

Keywords: economic sociology; debt; social networks; loans; sociology of credit

\section{Sumario}

1. Introducción

2. Las estructuras sociales de endeudamiento: formas comunitarias y formas mercantiles. Algunos

fundamentos para una sociología económica del endeudamiento

3. La participación en los espacios financieros y el desarrollo económico

4. Hipótesis y proposiciones
5. Fuente de datos, unidades de análisis y definición de las variables

6. Interpretación de los datos y verificación de las hipótesis

7. Un análisis jerárquico de la estructura social de endeudamiento: contexto social, económico e institucional

8. A modo de conclusión

Referencias bibliográficas

\section{Introducción}

En este trabajo, nos aproximaremos al estudio de la naturaleza formal e informal de los espacios financieros ${ }^{1}$. A partir de la explotación de los datos de la encuesta ISSP 2001, realizada en un total de 26 países, observamos el peso que adquieren en cada zona las orientaciones de naturaleza comunitaria, de tipo familiar y extrafamiliar y de mercado que declaran los individuos encuestados cuando se les pregunta a quién acudirían en caso de necesitar una gran cantidad de dinero. Es importante subrayar que no se trata de establecer el comportamiento efectivo (si pidió un crédito, de qué cantidad se trataba o por cuánto tiempo y tipo de interés lo hizo), sino el peso que tienen las orientaciones o los grupos de referencia en cada uno de los países. Grupos de referencia que,

1. Este trabajo ha sido realizado dentro de las actividades animadas por el proyecto PSI200801937 del Ministerio de Ciencia e Innovación dirigido por Félix Requena, de la Universidad de Málaga. 
como diría Merton (1964) en su obra Teoría y.estructura sociales, encuentran su anclaje en la estructura social. Pretendemos observar cuáles son las representaciones sociales dominantes en cada país, interesándonos por conocer el peso de los diferentes tipos de estructuras sociales de endeudamiento.

En este trabajo, se pone a prueba la utilidad del concepto de estructura social de endeudamiento y su relación con el de grupos de referencia. De este modo, partimos de un marco teórico-conceptual que interesa también a la sociología de los mercados (Swedberg y Smelser, 2005) y, más en particular, a una sociología del endeudamiento en la que la deuda se interpreta en términos de una relación social (Knorr Cetina y Preda, 2012; Carruthers y Ariovich, 2010). De acuerdo con este enfoque que hunde raíces en la sociología clásica (Simmel, 1900; Herranz, 2008), comenzamos, en el apartado 2, profundizando en el significado de este concepto. A continuación, y en el apartado 3, se observan algunos indicadores sobre las prácticas formales e informales de endeudamiento y de ahorro a escala global y se discuten las limitaciones de estas fuentes, así como la complejidad que pueden adoptar las estructuras sociales de endeudamiento. En los dos apartados siguientes, se presentan las hipótesis y las proposiciones básicas de la investigación, la fuente de datos, las unidades de análisis y la definición de las variables utilizadas. En los apartados 6 y 7, se contrastan las proposiciones formuladas y se presenta una clasificación de países en función del modo en que se configuran las diversas estructuras sociales de endeudamiento. Finalmente, en el apartado 8, se recogen las conclusiones.

\section{Las estructuras sociales de endeudamiento: formas comunitarias $y$ formas mercantiles. Algunos fundamentos para una sociología económica del endeudamiento}

La sociología económica considera que los actores económicos, sus metas y sus comportamientos están incrustados y adquieren significado en contextos de interacción social (Weber, 1922). Por este motivo, presentamos el endeudamiento desde una perspectiva que se aleja de la metodología individualista radical que caracteriza al modelo neoclásico, definiendo la idea de estructura social de endeudamiento.

El concepto de estructura social de endeudamiento (ESE) hace referencia a un espacio de relaciones sociales en el que los «acreedores» y los «deudores» constituyen el eje de la relación. Esta idea, aunque interesante como punto de partida, debe de considerarse provisional. Desde una perspectiva afín a la que adopta Portes (2013), se pueden combinar tres grandes enfoques: el relacional (redes y capital social), el institucional y, finalmente, el de la economía política, que enfatiza el papel del poder, la política y las relaciones de desigualdad.

La idea de estructura social de endeudamiento supone la presencia de unas relaciones relativamente estables entre los acreedores y los deudores, cuyo desempeño puede entenderse en términos de expectativas de rol y de "guiones culturales e institucionales». Estos procesos de interacción social, que tienen lugar de un modo directo, personal y en contextos de proximidad, se desarro- 
llan en una densa red de relaciones sociales (Granovetter, 1985). Las relaciones y las obligaciones mutuas, así como los derechos y los deberes que se contraen en los acuerdos entre el deudor y el acreedor, se acompañan a su vez de un conjunto de roles desempeñados por distintos actores, como, por ejemplo: las agencias de calificación, los registradores del contrato, los observadores del comportamiento del deudor, los avalistas, los jueces, etc. Se trata, pues, de una urdimbre institucional que contribuye a definir a los actores en juego, a los presupuestos de la acción y a reducir la incertidumbre.

En consecuencia, los procesos de endeudamiento y de desendeudamiento que dan vida a esta estructura social no tienen lugar en un vacío social ni responden tan solo a los deseos y a las preferencias de los actores directamente implicados. En efecto, intervienen expectativas y obligaciones definidas bien como normas sociales y/o bien como reglas jurídicas que los actores no han definido directamente, dado que son externas al contrato propiamente dicho (Durkheim, 1893).

Esta definición de ESE que se inspira en la perspectiva interaccionista y reticular que propone Granovetter (1985), así como en la perspectiva institucional (Nee y Ingram, 1998), puede combinarse y ganar en capacidad explicativa, incorporando la perspectiva de la economía política. La economía política, como sostiene Portes (2013), obliga a pensar en las relaciones de poder y en las estructuras de clases, en la medida en que afectan a las reglas de juego y a la naturaleza de las relaciones de competencia y de conflicto (Fligstein, 2001; Bourdieu, 2000).

Como ilustración de este concepto, cabe pensar en la relación entre la deuda, la estructura de clases y la posición en el mercado de trabajo. Desde esta perspectiva, se entiende que aquellos individuos que ocupan posiciones sociales periféricas y que son vulnerables en el mercado de trabajo pueden autoexcluirse y/o carecer de la "calificación» necesaria para acceder a un préstamo. Incluso, en el caso de disponer de un crédito y ante situaciones imprevistas (enfermedad, pérdida de empleo, etc.), pueden incurrir en situaciones de sobreendeudamiento. Este riesgo se incrementa en situaciones de crisis económica y sucede en mayor medida cuando los servicios públicos de protección social son precarios o inexistentes. En este caso, ya se trate de los pobres del tercer mundo (Collins et al., 2009), de una clase media fragilizada (Sullivan et al., 2000) o de grupos marginales del primer mundo, no recurren a los lazos débiles, sino al vigor de los lazos fuertes (Granovetter, 2003). Las redes sociales fuertes desempeñan un papel importante, tanto en el terreno económico como en el de los cuidados y el apoyo emocional (Requena, 2011).

En este sentido, y retomando la perspectiva teórica, los grupos de referencia fuertes o débiles en los que se piensa para pedir un préstamo encuentran su anclaje en diversas estructuras del tipo Gemeinschaft y Gesellschaft (Tönnies, 1887), que permiten calificar en su forma más pura dos tipos ideales de «estructuras sociales de endeudamiento». Sin embargo, en la realidad social, entre estos dos modelos «ideales», que denominaremos «ESE comunitarias» y «ESE no comunitarias", es posible observar situaciones mixtas de endeudamiento que se destacarán posteriormente. 


\section{La participación en los espacios financieros y el desarrollo económico}

El recurso a las ESE comunitarias y no comunitarias, así como a los espacios formales e informales, varía según el desarrollo y la estructura social de cada país. En los siguientes apartados, presentamos algunas evidencias empíricas sobre las características que pueden adoptar dichas estructuras.

\subsection{Las estructuras sociales de endeudamiento de naturaleza formal}

En el mundo desarrollado y durante el periodo de crecimiento anterior a la crisis de 2007, el motor de la expansión económica se basó en un intenso endeudamiento. Debido al papel estratégico desempeñado por las grandes corporaciones financieras en el estímulo de la demanda agregada, este modelo se ha calificado de "keynesianismo privado» (Crouch, 2011). En expresión de Bauman, la libreta de ahorro, símbolo de una "sociedad de productores», es desplazada, durante la década de 1990 y los inicios del siglo XxI, por las tarjetas de crédito. "Vivir a crédito» se ha convertido en una "opción razonable» y de «sentido común» en una «sociedad de consumidores» promovida por las entidades financieras y que echa profundas raíces en los hábitos y en las disposiciones de muchos jóvenes en la gran mayoría de países más desarrollados (Bauman, 2010: 110-111). Hoy en día, tras la crisis del año 2007, la posición de "endeudado» en muchos países se ha convertido en un severo lastre, de modo que estados, empresas, familias e individuos se ven sometidos a un lento proceso de desendeudamiento.

Sin embargo, a pesar de los intensos procesos de bancarización (De Blic y Lazarus, 2007), de endeudamiento y de financiarización de la economía y de la vida (Ingham, 2010; Fligstein y Goldstein, 2015; Carruthers, 2015), así como de la difusión del dinero de plástico (Carruthers y Ariovich, 2010) — circunstancias habituales en los países más desarrollados-, la situación dista mucho de ser la misma en los países pobres y emergentes. En estos países, si bien con diferencias destacables, una gran parte de la población carece de una cuenta corriente, el porcentaje de personas que se endeudan o que ahorran a través de canales formales es reducido y, por el contrario, es significativo el peso del préstamo y del ahorro informal.

Todo indica que, tradicionalmente, según se recoge en la tabla 1, la banca no ha estado interesada en una clientela con ingresos muy bajos e inestables, ni presta atención a las necesidades de financiación de los pequeños negocios. Los microcréditos han tratado de paliar esta situación de exclusión financiera. En el modelo del Grameen Bank y en otras instituciones de Bangladesh, se ofrecían pequeñas cantidades de dinero a un grupo de mujeres interesadas en poner en marcha y mantener pequeños negocios. En el caso de incumplimiento de las condiciones de reintegro por parte de algún miembro, el grupo respondía societariamente. Por este motivo, los participantes se encontraban sometidos a un fuerte control social, dado que se ponía en juego su reputación ante el grupo y ante la comunidad más inmediata, caracterizada por densas redes de intercambio comunitario. 
Pero, con la extensión del sistema en la década de 1990, tanto en Bangladesh como en otros lugares de Asia, América Latina y África, el esquema de negocio cambia radicalmente. La industria financiera que se originó con el microcrédito pasa a ser dirigida por entidades de alcance global, concede préstamos de todo tipo para consumo e inversión de acuerdo con criterios estrictos de mercado, fundados en la sostenibilidad y el éxito del negocio financiero. El modelo social y de empoderamiento de la mujer está ausente en su mayor parte. Este nuevo formato de banca comercial ha contribuido al sobreendeudamiento múltiple de los pobres, lo cual ha provocado burbujas que han desembocado en importantes crisis de las microfinanzas, como ha sucedido en Andhra Pradesh, Bolivia, Pakistán, Marruecos, Bosnia-Herzegovina y Nicaragua (Mader, 2015).

Ante este tipo de situaciones, los pobres sobreendeudados han recurrido y han vuelto a activar, cuando estaban disponibles, las redes sociales fuertes y las formas de apoyo comunitario (Chen y Rutherford, 2013).

Aunque los microcréditos pudieron contribuir a reducir la discriminación femenina en el acceso a la propiedad y a un limitado mercado de capitales del medio rural (Amartya Sen, 2000), los análisis sociológicos y antropológicos realizados sobre el terreno en la India y Bangladesh revelan que las mujeres que intentan gestionar su microcrédito han tenido que enfrentarse a una estructura patriarcal que o bien limitaba su autonomía (Sanyal, 2014) o bien llegaba a fagocitar el pequeño crédito concedido, lo cual reducía a la mujer a un papel de intermediaria (Karim, 2011).

\subsection{El papel de las redes informales de endeudamiento}

En los países pobres, y ante las dificultades de acudir a las entidades financieras de carácter formal, se recurre con frecuencia al apoyo de familiares, amigos, conocidos y vecinos, o bien a otras instituciones de naturaleza informal, para hacer frente a necesidades básicas (salud, educación, etc.) o a gastos derivados de rituales sociales (funerales, celebraciones, etc.); otras veces se trata de sacar adelante pequeños negocios, de resolver problemas de liquidez ante unos ingresos muy inestables o de refinanciar y poder responder a situaciones de sobreendeudamiento.

En la tabla 1, se recogen las diferencias entre países según su nivel de ingresos atendiendo a diversos indicadores de bancarización y de endeudamiento no bancario e informal, así como de ahorro informal. Los datos han sido obtenidos a partir de las informaciones que ofrece el Global Findex Database (World Bank, 2014). Si comparamos los países con ingresos más altos con los situados en los otros tres tramos, se desprende que son los primeros los que disponen en mayor medida de una tarjeta de crédito $(48,9 \%)$ y los que acuden con más frecuencia a un banco para pedir dinero $(17,3 \%)$. Por el contrario, en los países pobres es donde se recurre más frecuentemente al prestamista informal $(6,5 \%)$ y, sobre todo, a los familiares y amigos $(34,9 \%)$, en comparación con los que utilizan esta red en países con ingresos superiores. Un comportamiento semejante se extrae a partir de los datos de la misma fuente para el año 2011, 
Tabla 1. Porcentaje de personas adultas ( $<15$ años) que disponen de cuenta y/o de tarjeta o han ahorrado o pedido dinero en los últimos doce meses según el grupo de nivel de ingresos

\begin{tabular}{lrrrrr}
\hline & \multicolumn{5}{c}{ Nivel de ingresos } \\
\cline { 2 - 6 } & Bajo & Medio bajo & Medio alto & Alto & Total \\
\hline Cuenta en institución financiera & 22,3 & 41,8 & 70,4 & 90,6 & 60,7 \\
Tarjeta de crédito & 1,1 & 3,7 & 16,8 & 48,9 & 17,6 \\
Tarjeta de débito & 6,6 & 21,2 & 45,9 & 75,1 & 40,1 \\
Ahorro & 46,5 & 45,6 & 62,7 & 67,0 & 56,5 \\
Ahorro en institución financiera & 9,9 & 14,8 & 32,2 & 46,7 & 27,4 \\
Ahorro en grupo de ahorro informal & 16,3 & 12,4 & 4,9 & - & - \\
Pidió dinero prestado & 52,5 & 47,4 & 37,7 & 38,3 & 42,4 \\
Pidió prestado a institución financiera & 8,6 & 7,5 & 10,4 & 17,3 & 10,7 \\
Pidió prestado a prestamista & 6,5 & 8,5 & 2,6 & 0,9 & 4,6 \\
Pidió prestado a familia y/o a amigos & 34,9 & 33,1 & 24,0 & 15,0 & 26,2 \\
\hline
\end{tabular}

Fuente: World Bank.

lo que permite sostener que existe una cierta estabilidad en la estructura de prácticas sociales de endeudamiento.

Sin embargo, estos datos no reflejan adecuadamente la compleja naturaleza de las redes de endeudamiento informal. En diversos estudios de caso basados en entrevistas en profundidad realizados en la India, Bangladesh y Sudáfrica, se pone de relieve cómo los pobres recurren a sus familiares, amigos, vecinos y compañeros de trabajo para pedir un préstamo y utilizan otras vías de apoyo comunitario. En Portfolios of the Poor (Collins et al., 2009), se constata la variedad de estrategias, formales e informales, que adoptan los pobres para poder hacer frente a múltiples e imprevisibles situaciones de emergencia en su vida. Con mucha frecuencia, se piden pequeños préstamos sin interés que deben devolverse en períodos muy cortos de tiempo a familiares, amigos o vecinos, quienes esperan igualmente y de un modo recíproco que se les ayude en caso de necesidad (Collins et al., 2009: 50). De esta forma, el préstamo no se resuelve exclusivamente con la devolución, sino que se incrusta socialmente, de modo que se genera la obligación de proceder en correspondencia.

\subsection{El papel de las estructuras comunitarias en las formas de endeudamiento}

Existen numerosos estudios que documentan el desarrollo de diversas formas de apoyo financiero informal, como es el caso de las asociaciones de ahorro y crédito rotativo (ROSCA) o de otros tipos de préstamo no regulado oficialmente en diversos países de Latinoamérica (Adams y Canavesi Shonero, 1989), África (Aryeetey, 2001) y Asia (Tsai, 2004).

Las ROSCA son un tipo de estructuras comunitarias, como sería el caso de los grupos informales creados por compañeros de trabajo de una empresa, los miembros de un grupo étnico, religioso o la comunidad de vecinos de un barrio, que contribuyen a mantener un fondo común del que hacen uso de 
un modo rotativo y regular. Este tipo de institución informal, salvo casos excepcionales que sirven para respaldar iniciativas empresariales, se especializa en la generación de ahorro para hacer frente a la compra de bienes de consumo. La estructura comunitaria que sirve de fundamento para este tipo de práctica facilita la socialización y el control del comportamiento (económico y social), además de generar obligaciones en las que se pone en juego la reputación de los individuos y de sus familias (Biggart, 2001). La presencia en diversos continentes de una institución con rasgos parecidos a la ROSCA parece responder, tal y como sostiene Biggart, más a una lógica situacional que a un proceso de isomorfismo, de difusión o de imitación cultural.

Los primeros trabajos realizados sobre la economía étnica (Light, 1972) mostraban de qué manera los fenómenos de «discriminación» contribuyen a explicar el desarrollo de sistemas informales de acceso al crédito del tipo ROSCA (Light, 2005). Además, Alejandro Portes, refiriéndose también a los EE. UU., interpreta dichas prácticas como una respuesta de las comunidades con identidades étnicas muy marcadas (entre otras, judíos, japoneses, coreanos, salvadoreños y cubanos) ante un contexto social, económico-financiero y contractual adverso. En un entorno hostil, la confianza en que nadie abandonará el grupo y el control que se deriva de la existencia de estrechos vínculos entre los miembros son condiciones que facilitan el funcionamiento de esta institución y que ilustran sobre los efectos del «capital social» (Portes, 2013; Granovetter, 1985 y 2003).

En esta línea de investigación sobre las formas comunitarias y particularistas de endeudamiento, también se descubre, confirmando argumentos adelantados por la sociología económica clásica, la existencia de múltiples formas de mestizaje entre lo formal y lo informal. Por ejemplo, en los EE. UU., las asociaciones de ahorro y crédito rotativo han tendido a formalizarse jurídicamente. Otras veces son los bancos los que ofrecen un trato preferente a miembros de su propia etnia o comunidad, que, de acuerdo con una racionalidad práctica y situacional, consiguen reducir el riesgo de impago. Con los denominados "prestamos de carácter», los bancos cubanos ubicados en el enclave de Miami actuan así. En este caso, los deudores ponen en juego su reputación, su prestigio personal y el de su familia (Portes, 2013).

Estos ejemplos son bien ilustrativos acerca de cómo, entre las definiciones puras o típicas ideales de estructura social comunitaria y no comunitaria, existen muchas zonas de sombra y procesos de tránsito entre unas y otras.

El análisis empírico que presentamos no estudia estas instituciones informales de préstamo, pero sí permite sacar a la luz algunos rasgos sobre el peso que tienen los grupos de referencia de naturaleza comunitaria (posiciones familiares y posiciones extrafamiliares) en las orientaciones que adoptan los individuos de diversos países cuando se les pregunta acerca de a quién le pedirían un préstamo si necesitaran una gran cantidad de dinero. Se trata de capturar algunas de las características de «las redes de referencia» o «la estructura reticular de referencia» $y$, a través de estas, obtener una imagen del modo en que se define socialmente la ESE. 


\section{Hipótesis y proposiciones}

Dentro de este marco teórico animado por el interés en conocer las estructuras sociales de endeudamiento y a la luz de los datos disponibles de la encuesta ISSP 2001, formulamos las siguientes proposiciones e hipótesis:

Hipótesis 1: cuanto más desarrollados son los paises, más peso adquieren las orientaciones hacia los préstamos bancarios. Hipótesis 2: a medida que los paises van siendo más desarrollados, las orientaciones hacia las estructuras sociales de proximidad son menos relevantes. Esta segunda hipótesis nos sugiere dos proposiciones subordinadas. Hipótesis 2.1.: el desarrollo económico se acompaña de una transformación en la distribución de las orientaciones dentro del grupo parental, de modo que ganan peso las posiciones que pertenecen al núcleo familiar y se reduce la heterogeneidad de posiciones propias del círculo familiar extenso. Hipótesis 2.2.: el peso del conjunto de orientaciones hacia posiciones situadas en las estructuras sociales de proximidad no familiar se reduce con el desarrollo económico y se acompaña de una transformación en su composición interna, con lo que decrece la variedad de figuras a las que se podría recurrir. Y, finalmente, la hipótesis 3: a medida que los paises son más pobres, aumenta la presencia de personas que, en caso de necesitar una gran cantidad de dinero, afirman que no acudirian a nadie.

El examen de estas proposiciones se realiza mediante la construcción de un conjunto de indicadores (apartado 5) que nos permite aproximarnos a las pautas de comportamiento social del endeudamiento en cada país, como son la orientación hacia la banca, la orientación de proximidad - pareja, familiar y no familiar- y la no orientación. Además, se profundiza en el estudio de la heterogeneidad de la composición de los grupos de referencia social mediante la construcción de algunos ratios que indican el peso que tiene cada grupo de referencia (pareja, familia y amigos, ascendentes, laterales, etc.) dentro de las orientaciones de proximidad y de no proximidad. Se apoya el análisis contemplando algunas características sociodemográficas (edad, sexo y ocupación) que pueden tener interés para explicar el modo en que se representan las distintas oportunidades de endeudamiento.

Tras poner a prueba estas hipótesis, se lleva a cabo un análisis de conglomerados jerárquicos para observar si existen grupos de países que, a partir de las variables construidas, presentan una identidad definida o un comportamiento similar. Los resultados de esta agrupación se acompañan de datos de naturaleza macroeconómica y demográfica que permiten contextualizar y comprender el significado y las limitaciones de esta clasificación.

\section{Fuente de datos, unidades de análisis y definición de las variables}

Los datos empleados proceden de la encuesta Social Relations and Social Support Systems que se llevó a cabo en 2001 dentro del International Social Survey Program (ISSP Research Group, 2003). En nuestro caso, explotamos la siguiente pregunta: «Imagine que usted necesita pedir prestada una gran cantidad de dinero, ¿a quién acudiría en primer lugar para que le ayudara?». El abanico 
de alternativas de respuesta que se recogen en la encuesta es exhaustivo y en él se detallan las diversas posiciones familiares, no familiares e institucionales a las que se podría recurrir ${ }^{2}$. Tal y como se indicó en la introducción, no se pretende observar el comportamiento efectivo de los individuos entrevistados, sino de determinar sus posibles orientaciones.

La encuesta fue realizada a un total de 38.437 individuos repartidos entre los 29 países participantes, con tamaños muestrales por cada uno superiores a las 1.000 personas. La selección dentro de los países fue mayoritariamente aleatoria estratificada, empleando características sociodemográficas (áreas geográficas, edad, género, nivel educativo, etc.) para garantizar la representatividad de la población adulta que reside en hogares privados, con un nivel de error global del 3\% aproximado para un nivel de confianza del 95\%. El cuestionario contiene fundamentalmente preguntas relativas al estudio de las redes sociales y a la participación ciudadana. Incluye también variables sociodemográficas del entrevistado que, en algunos casos, permitieron realizar la posestratificación de la muestra.

De los 29 países participantes, se seleccionaron 26 en base a criterios de disponibilidad y validez de la información desagregada que permitiese construir las variables agregadas empleadas en el análisis. Así pues, se excluyeron del estudio los datos de Alemania del Este, Israel, Irlanda del Norte y Holanda.

La unidad de análisis empleada no fueron los individuos que participaban en cada una de las encuestas nacionales, sino cada uno de los países ${ }^{3}$. Se decidió la agregación a nivel de país para poder establecer las pautas de comportamiento a nivel macro (Snijders y Bosker, 1999). Fueron descartados otros tipos de análisis, como el multinivel o los modelos logísticos, pues nos centramos en el estudio de las orientaciones predominantes en cada país como elemento diferenciador de las ESE. Este otro tipo de técnicas permitirían introducir variables explicativas de los individuos o de los agregados contextuales de la zona para analizar los diferentes comportamientos individuales (Puntscher et al., 2016; Andréu Abelá, 2011). Se incluyen quince países desarrollados y muy desarrollados que ocupan posiciones diferentes en la tabla de clasificación de renta per cápita; otros con niveles de desarrollo inferior, como algunos que pertenecieron a la antiguamente denominada Europa del Este, y, finalmente, cinco países, Sudáfrica, Chile, Brasil, Rusia y Filipinas, muchos de ellos de gran tamaño en términos geográficos y de población, pero con acusadas desigualdades internas (Brasil, Sudáfrica y Rusia) y que se reconocen actualmente como emergentes.

2. Marido, mujer, pareja (01); madre (02); padre (03); hija (04); hijo (05); hermana (06); hermano (07); algún otro pariente de sangre (08); algún otro pariente político (09); padrino (10); amigo íntimo (11); vecino (12); algún compañero de trabajo (13); jefe (14); agencia gubernamental o de servicios sociales (15); banco o unión de crédito (16); préstamo privado (17); otra persona (18); nadie (19), y NS/NC (20).

3. Alemania (D-W), Australia (AUS), Austria (A), Brasil (B), Canadá (CDN), Chile (RCH), Chipre (CY), Dinamarca (DK), Eslovenia (SLO), España (E), Estados Unidos (USA), Filipinas (RP), Finlandia (SF), Francia (F), Gran Bretaña (GB), Hungría (H), Italia (I), Japón (J), Letonia (LV), Noruega (N), Nueva Zelanda (NZ), Polonia (PL), Republica Checa (CZ), Rusia (RUS), Sudáfrica (ZA) y Suiza (CH). 
Todos son calificados por la ONU con un índice de desarrollo humano alto, a excepción de Rusia, Filipinas, Brasil y Sudáfrica, con un IDH medio.

Fundamentalmente, nos interesa analizar y explicar el comportamiento de tres variables (tabla 2): orientación hacia la banca, o porcentaje de la población de cada país que pediría dinero «a la banca»; orientación de proximidad, o peso en cada país de los que acudirían a personas que ocupan una posición de proximidad, sea familiar o no familiar, y orientación hacia nadie, o porcentaje de la población de cada país que manifiesta que «no se lo pediría a nadie».

De todas ellas, la más compleja es la variable relativa a la orientación de proximidad, construida a partir de varios procesos de agregación de los datos originales, según las posiciones sociales a las que se pediría una gran cantidad de dinero y que fueron mencionadas por los entrevistados de cada uno de los países. En esta variable, se incluyen todas las orientaciones hacia posiciones específicas, ya sea que se refieran a miembros de la familia (en cuyo caso hablaremos de orientaciones de proximidad familiar o grupo de referencia familiar) o a miembros de la estructura social de proximidad «no familiar». En el primer tipo, las orientaciones de proximidad familiar, se incorporan todas aquellas personas que pedirían prestado a su pareja, a algún ascendiente, a algún descendiente, a algún hermano o hermana (vínculo lateral), a algún pariente de sangre, a algún pariente político o a algún padrino. En el segundo tipo, en las orientaciones de proximidad no familiar, se incluyen los que se lo pedirían a algún amigo íntimo, a algún vecino, a algún compañero de trabajo o, finalmente, al jefe 4 .

A partir de estas variables que resultan de diferentes niveles de agregación, se han construido los siguientes ratios:

1. El peso del porcentaje de las orientaciones de proximidad familiar respecto al porcentaje de las orientaciones de proximidad en general y multiplicado por 100 .

2. El peso o ratio entre el porcentaje de una orientación hacia una posición — por ejemplo: el porcentaje de orientación a la pareja o el porcentaje de orientación a los ascendentes, etc. - respecto al porcentaje del conjunto de orientaciones de proximidad familiar y multiplicado por 100 .

3. Análogamente procedemos con las configuraciones de las estructuras sociales de proximidad no familiar. Entre otros ratios posibles, en la tabla 2, se presentan los pesos de algunas de las orientaciones de proximidad no familiar - por ejemplo: si piensan que se lo pedirían a los amigos íntimos - respecto al porcentaje de las orientaciones de proximidad no familiar multiplicado por 100.

Como variable explicativa, hemos elegido el PIB per cápita para analizar la presencia de pautas diferentes según el nivel de desarrollo. Otros factores observados que hipotéticamente pueden mediar entre el nivel de desarrollo del país y las orientaciones son la edad, el género y el hecho de estar o no ocupado

4. No se incluyen «los servicios sociales», pues su peso es residual y no encuentran una adecuada ubicación en la tipología. 
Tabla 2. Orientaciones y ratios

\begin{tabular}{|c|c|c|c|c|c|c|c|c|c|c|c|c|c|c|}
\hline & \multirow[b]{2}{*}{ PIBpc } & \multicolumn{6}{|c|}{ Orientaciones } & \multicolumn{7}{|c|}{ Ratios } \\
\hline & & Nadie & Banca & Pareja & PrNoFam & PrFam & $\mathrm{Pr}$ & Fam/Pr & P/Fam & Asc/Fam & Desc/Fam & Lat/Fam & 0tr/Fam & Int/NoFam \\
\hline Australia (AUS) & 26730 & 5,56 & 25,08 & 38,81 & 2,94 & 65,52 & 68,46 & 95,7 & 59,23 & 18,33 & 13,09 & 6,86 & 2,49 & 80,56 \\
\hline Alemania (D-W) & 25350 & 6,53 & 37,11 & 18,06 & 3,70 & 52,45 & 56,15 & 93,41 & 34,44 & 42,32 & 9,34 & 10,37 & 3,53 & 79,41 \\
\hline Gran Bretaña (GB) & 24160 & 9,38 & 32,15 & 24,03 & 1,60 & 55,95 & 57,55 & 97,22 & 42,94 & 37,01 & 6,95 & 7,16 & 5,93 & 71,43 \\
\hline Estados Unidos (USA) & 34320 & 11,86 & 14,87 & 12,74 & 6,28 & 66,46 & 72,74 & 91,36 & 19,17 & 46,60 & 8,66 & 15,98 & 9,59 & 85,92 \\
\hline Austria (A) & 25370 & 11,82 & 29,86 & 17,84 & 3,31 & 54,91 & 58,22 & 94,32 & 32,48 & 39,78 & 14,23 & 8,58 & 4,93 & 96,97 \\
\hline Hungría (H) & 12340 & 19,05 & 24,14 & 4,16 & 7,51 & 49,03 & 56,54 & 86,71 & 8,48 & 36,25 & 24,49 & 14,64 & 16,14 & 65,18 \\
\hline Italia (I) & 24670 & 5,82 & 25,48 & 12,74 & 3,41 & 65,30 & 68,71 & 95,04 & 19,51 & 44,24 & 16,90 & 14,29 & 5,07 & 64,71 \\
\hline Noruega $(\mathrm{N})$ & 29620 & 1,89 & 42,86 & 24,8 & 2,70 & 52,43 & 55,12 & 95,11 & 47,30 & 39,07 & 4,50 & 5,27 & 3,86 & 77,50 \\
\hline Rep. Checa (CZ) & 14720 & 10,86 & 18,30 & 14,12 & 9,86 & 60,57 & 70,43 & 86,00 & 23,31 & 40,69 & 16,14 & 13,38 & 6,48 & 69,49 \\
\hline Eslovenia (SL0) & 17130 & 8,81 & 18,46 & 17,44 & 10,85 & 61,60 & 72,45 & 85,02 & 28,31 & 30,57 & 15,96 & 16,11 & 9,04 & 81,20 \\
\hline Polonia (PL) & 9450 & 11,76 & 16,32 & 8,04 & 11,02 & 60,65 & 71,67 & 84,62 & 13,25 & 35,93 & 25,00 & 18,03 & 7,79 & 58,65 \\
\hline Rusia (RUS) & 7100 & 13,66 & 0,40 & 3,65 & 29,36 & 56,43 & 85,79 & 65,77 & 6,47 & 32,89 & 19,77 & 21,90 & 18,97 & 59,8 \\
\hline Nueva Zelanda (NZ) & 19170 & 6,43 & 45,8 & 19,82 & 1,43 & 45,71 & 47,14 & 96,97 & 43,36 & 34,57 & 9,77 & 8,01 & 4,30 & 75,00 \\
\hline Canadá (CDN) & 27130 & 4,86 & 47,11 & 18,15 & 2,11 & 45,55 & 47,66 & 95,58 & 39,84 & 35,81 & 7,04 & 9,05 & 8,25 & 73,91 \\
\hline Rep. Filipinas (RP) & 3840 & 8,18 & 6,43 & 11,35 & 14,61 & 69,53 & 84,14 & 82,64 & 16,33 & 24,61 & 15,49 & 26,29 & 17,29 & 50,86 \\
\hline Japón (J) & 25130 & 4,86 & 21,56 & 20,43 & 2,35 & 68,94 & 71,3 & 96,7 & 29,63 & 42,51 & 13,88 & 11,23 & 2,75 & 54,84 \\
\hline España (E) & 20150 & 3,81 & 21,10 & 14,92 & 3,31 & 71,61 & 74,92 & 95,59 & 20,83 & 44,97 & 18,46 & 12,07 & 3,67 & 87,18 \\
\hline Letonia (LV) & 7730 & 18,1 & 10,3 & 7,50 & 25,70 & 45,20 & 70,9 & 63,75 & 16,59 & 27,88 & 18,81 & 18,58 & 18,14 & 59,53 \\
\hline Francia $(\mathrm{F})$ & 23990 & 7,06 & 37,47 & 13,68 & 3,94 & 51,15 & 55,09 & 92,85 & 26,74 & 48,84 & 6,10 & 10,76 & 7,56 & 81,13 \\
\hline Chipre (CY) & 21190 & 0,00 & 50,60 & 19,09 & 3,38 & 45,73 & 49,11 & 93,12 & 41,74 & 43,48 & 5,22 & 6,96 & 2,61 & 61,76 \\
\hline Rep. Chile (RCH) & 9190 & 12,86 & 14,55 & 12,32 & 12,79 & 58,86 & 71,65 & 82,14 & 20,94 & 35,13 & 11,67 & 20,94 & 11,33 & 46,84 \\
\hline Dinamarca (DK) & 29000 & 5,68 & 52,05 & 16,64 & 1,58 & 40,46 & 42,03 & 96,25 & 41,13 & 41,13 & 7,60 & 3,51 & 6,63 & 85,00 \\
\hline Suiza (CH) & 28100 & 8,00 & 20,90 & 14,40 & 7,80 & 62,60 & 70,4 & 88,92 & 23,00 & 42,81 & 8,47 & 9,90 & 15,81 & 71,79 \\
\hline Brasil (B) & 7360 & 16,08 & 19,01 & 12,04 & 12,82 & 52,10 & 64,92 & 80,26 & 23,12 & 35,95 & 12,94 & 15,38 & 12,62 & 47,84 \\
\hline Sudáfrica (ZA) & 11290 & 12,75 & 17,27 & 8,16 & 19,96 & 49,66 & 69,62 & 71,33 & 16,43 & 28,39 & 14,75 & 23,84 & 16,59 & 44,05 \\
\hline \multirow[t]{2}{*}{ Finlandia (SF) } & 24430 & 5,56 & 38,66 & 24,47 & 2,03 & 53,3 & 55,33 & 96,34 & 45,92 & 39,15 & 3,94 & 6,76 & 4,23 & 92,59 \\
\hline & & 9,52 & 25,6 & 14,95 & 8,71 & 55,63 & 64,34 & 86,47 & 26,88 & 37,30 & 12,94 & 13,88 & 9,00 & 60,63 \\
\hline
\end{tabular}

Fuente: elaboración propia.

(parados más inactivos). La variable edad se categorizó del modo siguiente: jóvenes (entre 16 y 29 años), adultos maduros (entre los 30 y los 59 años) y mayores (todos aquellos que tienen 60 años o más).

Para dicho conjunto de factores, también se determinaron las orientaciones y los ratios anteriormente definidos. En la tabla 3, se presentan los resultados de estas variables para el segmento de adultos maduros en función de la ocupación.

\section{Interpretación de los datos y verificación de las hipótesis}

\subsection{Las orientaciones hacia la banca}

La orientación hacia la banca se incrementa con el nivel de vida y es un indicador que refleja el proceso de bancarización. Esta tendencia creciente se traduce 
Tabla 3. Orientaciones y ratios de la población adulta maduraen función de la ocupación

\begin{tabular}{|c|c|c|c|c|c|c|c|c|c|c|c|c|c|c|}
\hline & & \multicolumn{6}{|c|}{ Orientaciones } & \multicolumn{7}{|c|}{ Ratios } \\
\hline & & Nadie & Banca & Pareja & PrNoFam & PrFam & $\operatorname{Pr}$ & Fam/Pr & P/Fam & Asc/Fam & Desc/Fam & Lat/Fam & 0tr/Fam & Int/NoFam \\
\hline \multirow[t]{2}{*}{ Australia (AUS) } & No oc. & 5,00 & 18,57 & 54,29 & 3,57 & 72,86 & 76,43 & 95,33 & 74,51 & 13,73 & 4,90 & 5,88 & 0,98 & 80,00 \\
\hline & Ocup. & 3,17 & 28,12 & 43,20 & 2,23 & 66,11 & 68,34 & 96,73 & 65,35 & 21,69 & 3,38 & 7,32 & 2,25 & 75,00 \\
\hline \multirow[t]{2}{*}{ Alemania (D-W) } & No oc. & 7,69 & 36,36 & 28,67 & 0,70 & 54,55 & 55,24 & 98,73 & 52,56 & 24,36 & 6,41 & 8,97 & 7,69 & 100,00 \\
\hline & Ocup. & 4,19 & 40,58 & 17,28 & 4,71 & 50,52 & 55,24 & 91,47 & 34,20 & 46,63 & 2,07 & 14,51 & 2,59 & 77,78 \\
\hline \multirow[t]{2}{*}{ Gran Bretaña (GB) } & No oc. & 10,37 & 17,78 & 34,81 & 2,22 & 67,41 & 69,63 & 96,81 & 51,65 & 29,67 & 3,30 & 8,79 & 6,59 & 100,00 \\
\hline & Ocup. & 3,77 & 41,51 & 24,53 & 1,89 & 52,83 & 54,72 & 96,55 & 46,43 & 37,24 & 2,04 & 9,69 & 4,59 & 42,86 \\
\hline \multirow[t]{2}{*}{ Estados Unidos (USA) } & No oc. & 14,07 & 14,07 & 14,81 & 7,41 & 62,96 & 70,37 & 89,47 & 23,53 & 41,18 & 5,88 & 21,18 & 8,24 & 90,00 \\
\hline & Ocup. & 9,90 & 17,67 & 13,79 & 6,02 & 66,02 & 72,04 & 91,64 & 20,88 & 50,29 & 2,06 & 15,29 & 11,47 & 80,65 \\
\hline \multirow[t]{2}{*}{ Austria (A) } & No oc. & 10,42 & 28,47 & 26,39 & 4,17 & 56,94 & 61,11 & 93,18 & 46,34 & 24,39 & 13,41 & 7,32 & 8,54 & 100,00 \\
\hline & Ocup. & 8,40 & 35,43 & 23,36 & 4,99 & 51,18 & 56,17 & 91,12 & 45,64 & 37,95 & 3,08 & 6,67 & 6,67 & 94,74 \\
\hline \multirow[t]{2}{*}{ Hungría $(\mathrm{H})$} & No oc. & 24,15 & 25,08 & 5,88 & 9,60 & 41,18 & 50,77 & 81,10 & 14,29 & 26,32 & 23,31 & 24,06 & 12,03 & 70,97 \\
\hline & Ocup. & 12,15 & 34,41 & 4,45 & 10,32 & 42,71 & 53,04 & 80,53 & 10,43 & 45,02 & 8,53 & 15,64 & 20,38 & 50,98 \\
\hline \multirow[t]{2}{*}{ Italia (I) } & No oc. & 5,15 & 25,77 & 14,43 & 1,03 & 68,04 & 69,07 & 98,51 & 21,21 & 45,45 & 12,12 & 16,67 & 4,55 & 100,00 \\
\hline & Ocup. & 2,74 & 28,49 & 16,71 & 6,58 & 62,19 & 68,77 & 90,44 & 26,87 & 50,22 & 2,64 & 16,30 & 3,96 & 58,33 \\
\hline \multirow[t]{2}{*}{ Noruega (N) } & No oc. & 2,76 & 35,17 & 34,48 & 0,00 & 61,38 & 61,38 & 100,00 & 56,18 & 28,09 & 3,37 & 7,87 & 4,49 & - \\
\hline & Ocup. & 0,95 & 51,36 & 23,64 & 3,13 & 44,43 & 47,55 & 93,43 & 53,21 & 37,31 & 1,83 & 3,98 & 3,67 & 73,91 \\
\hline \multirow[t]{2}{*}{ Rep. Checa (CZ) } & No oc. & 12,95 & 18,71 & 15,83 & 14,39 & 53,96 & 68,35 & 78,95 & 29,33 & 20,00 & 30,67 & 9,33 & 10,67 & 75,00 \\
\hline & Ocup. & 8,65 & 25,00 & 15,98 & 10,90 & 55,26 & 66,17 & 83,52 & 28,91 & 40,48 & 11,22 & 13,61 & 5,78 & 58,62 \\
\hline \multirow[t]{2}{*}{ Eslovenia (SL0) } & No oc. & 7,69 & 26,15 & 26,92 & 11,54 & 54,62 & 66,15 & 82,56 & 49,30 & 9,86 & 18,31 & 15,49 & 7,04 & 80,00 \\
\hline & Ocup. & 4,14 & 22,07 & 22,99 & 13,79 & 60,00 & 73,79 & 81,31 & 38,31 & 26,44 & 3,83 & 18,01 & 13,41 & 90,00 \\
\hline \multirow[t]{2}{*}{ Polonia (PL) } & No oc. & 13,03 & 12,64 & 8,81 & 16,48 & 57,47 & 73,95 & 77,72 & 15,33 & 34,00 & 23,33 & 18,67 & 8,67 & 51,16 \\
\hline & Ocup. & 7,95 & 22,41 & 9,64 & 11,81 & 57,83 & 69,64 & 83,04 & 16,67 & 39,58 & 7,92 & 26,25 & 9,58 & 59,18 \\
\hline \multirow[t]{2}{*}{ Rusia (RUS) } & No oc. & 18,15 & 0,37 & 4,44 & 23,33 & 57,41 & 80,74 & 71,10 & 7,74 & 21,94 & 24,52 & 21,94 & 23,87 & 69,84 \\
\hline & Ocup. & 10,87 & 0,00 & 4,35 & 34,14 & 54,99 & 89,13 & 61,69 & 7,91 & 28,37 & 10,00 & 32,33 & 21,40 & 57,30 \\
\hline \multirow[t]{2}{*}{ Nueva Zelanda (NZ) } & No oc. & 7,14 & 30,61 & 29,59 & 1,02 & 60,20 & 61,22 & 98,33 & 49,15 & 28,81 & 6,78 & 5,08 & 10,17 & 100,00 \\
\hline & Ocup. & 2,35 & 54,51 & 18,59 & 1,81 & 41,34 & 43,14 & 95,82 & 44,98 & 35,37 & 2,62 & 12,23 & 4,80 & 60,00 \\
\hline Canadá (CDN) & No oc. & 2,68 & 41,61 & 23,49 & 1,34 & 53,69 & 55,03 & 97,56 & 43,75 & 26,25 & 6,25 & 15,00 & 8,75 & 50,00 \\
\hline & Ocup. & 2,11 & 50,86 & 17,85 & 2,30 & 44,53 & 46,83 & 95,08 & 40,09 & 40,52 & 2,16 & 6,90 & 10,34 & 91,67 \\
\hline Rep. Filipinas (RP) & No oc. & 8,82 & 5,88 & 17,16 & 13,24 & 70,59 & 83,82 & 84,21 & 24,31 & 13,89 & 10,42 & 34,72 & 16,67 & 55,56 \\
\hline & Ocup. & 6,85 & 8,52 & 10,19 & 19,07 & 64,26 & 83,33 & 77,11 & 15,85 & 20,75 & 12,97 & 31,70 & 18,73 & 46,60 \\
\hline Japón (J) & No oc. & 7,63 & 15,25 & 38,98 & 1,69 & 74,58 & 76,27 & 97,78 & 52,27 & 34,09 & 2,27 & 9,09 & 2,27 & 100,00 \\
\hline & Ocup. & 3,33 & 27,15 & 19,96 & 2,10 & 64,27 & 66,37 & 96,83 & 31,06 & 48,77 & 4,63 & 14,17 & 1,36 & 16,67 \\
\hline España (E) & No oc. & 2,44 & 22,44 & 19,51 & 4,88 & 70,24 & 75,12 & 93,51 & 27,78 & 40,28 & 11,81 & 16,67 & 3,47 & 90,00 \\
\hline & Ocup. & 3,70 & 25,64 & 21,65 & 4,56 & 65,81 & 70,37 & 93,52 & 32,90 & 41,99 & 5,63 & 15,58 & 3,90 & 87,50 \\
\hline Letonia (LV) & No oc. & 21,19 & 6,78 & 6,78 & 25,42 & 45,76 & 71,19 & 64,29 & 14,81 & 29,63 & 12,96 & 25,93 & 16,67 & 66,67 \\
\hline & Ocup. & 13,57 & 15,10 & 8,75 & 32,39 & 38,73 & 71,12 & 54,46 & 22,60 & 18,08 & 10,17 & 23,73 & 25,42 & 57,43 \\
\hline Francia (F) & No oc. & 7,56 & 37,21 & 11,05 & 2,33 & 51,74 & 54,07 & 95,70 & 21,35 & 48,31 & 7,87 & 14,61 & 7,87 & 100,00 \\
\hline & Ocup. & 2,83 & 36,16 & 16,16 & 5,86 & 55,15 & 61,01 & 90,40 & 29,30 & 52,38 & 0,73 & 10,62 & 6,96 & 72,41 \\
\hline Chipre (CY) & No oc. & 0,00 & 39,18 & 50,52 & 2,06 & 58,76 & 60,82 & 96,61 & 85,96 & 5,26 & 0,00 & 7,02 & 1,75 & 100,00 \\
\hline & Ocup. & 0,00 & 64,43 & 20,82 & 3,04 & 31,89 & 34,92 & 91,30 & 65,31 & 17,69 & 1,36 & 10,20 & 5,44 & 35,71 \\
\hline Rep. Chile (RCH) & No oc. & 15,38 & 9,62 & 20,51 & 7,69 & 66,03 & 73,72 & 89,57 & 31,07 & 22,33 & 10,68 & 24,27 & 11,65 & 70,83 \\
\hline & Ocup. & 11,48 & 22,18 & 11,48 & 18,68 & 46,50 & 65,18 & 71,34 & 24,69 & 29,71 & 9,62 & 26,78 & 9,21 & 42,71 \\
\hline Dinamarca (DK) & No oc. & 9,18 & 47,96 & 18,37 & 2,04 & 39,80 & 41,84 & 95,12 & 46,15 & 41,03 & 2,56 & 7,69 & 2,56 & 100,00 \\
\hline & Ocup. & 0,98 & 60,10 & 18,24 & 1,47 & 37,46 & 38,93 & 96,23 & 48,70 & 39,57 & 1,74 & 3,04 & 6,96 & 66,67 \\
\hline Suiza $(\mathrm{CH})$ & No oc. & 10,39 & 22,08 & 27,27 & 6,49 & 59,74 & 66,23 & 90,20 & 45,65 & 26,09 & 2,17 & 10,87 & 15,22 & 100,00 \\
\hline & Ocup. & 5,80 & 24,36 & 16,24 & 10,21 & 59,16 & 69,37 & 85,28 & 27,45 & 43,14 & 1,96 & 14,12 & 13,33 & 77,27 \\
\hline Brasil (B) & No oc. & 17,65 & 18,33 & 17,87 & 9,28 & 54,75 & 64,03 & 85,51 & 32,64 & 19,83 & 14,88 & 16,53 & 16,12 & 53,66 \\
\hline & Ocup. & 17,43 & 25,73 & 9,75 & 18,46 & 38,38 & 56,85 & 67,52 & 25,41 & 27,57 & 9,19 & 25,95 & 11,89 & 46,07 \\
\hline Sudáfrica (ZA) & No oc. & 16,05 & 13,49 & 9,88 & 18,26 & 52,09 & 70,35 & 74,05 & 18,97 & 23,44 & 13,39 & 28,13 & 16,07 & 47,77 \\
\hline & Ocup. & 7,60 & 28,60 & 6,28 & 30,91 & 31,90 & 62,81 & 50,79 & 19,69 & 25,39 & 8,29 & 30,57 & 16,06 & 33,16 \\
\hline Finlandia (SF) & No oc. & 9,46 & 33,78 & 29,05 & 3,38 & 53,38 & 56,76 & 94,05 & 54,43 & 21,52 & 3,80 & 11,39 & 8,86 & 100,00 \\
\hline & Ocup. & 3,18 & 46,28 & 28,31 & 0,91 & 48,46 & 49,36 & 98,16 & 58,43 & 28,09 & 1,12 & 7,12 & 5,24 & 80,00 \\
\hline
\end{tabular}

Fuente: elaboración propia. 
Figura 1. Orientaciones hacia la banca

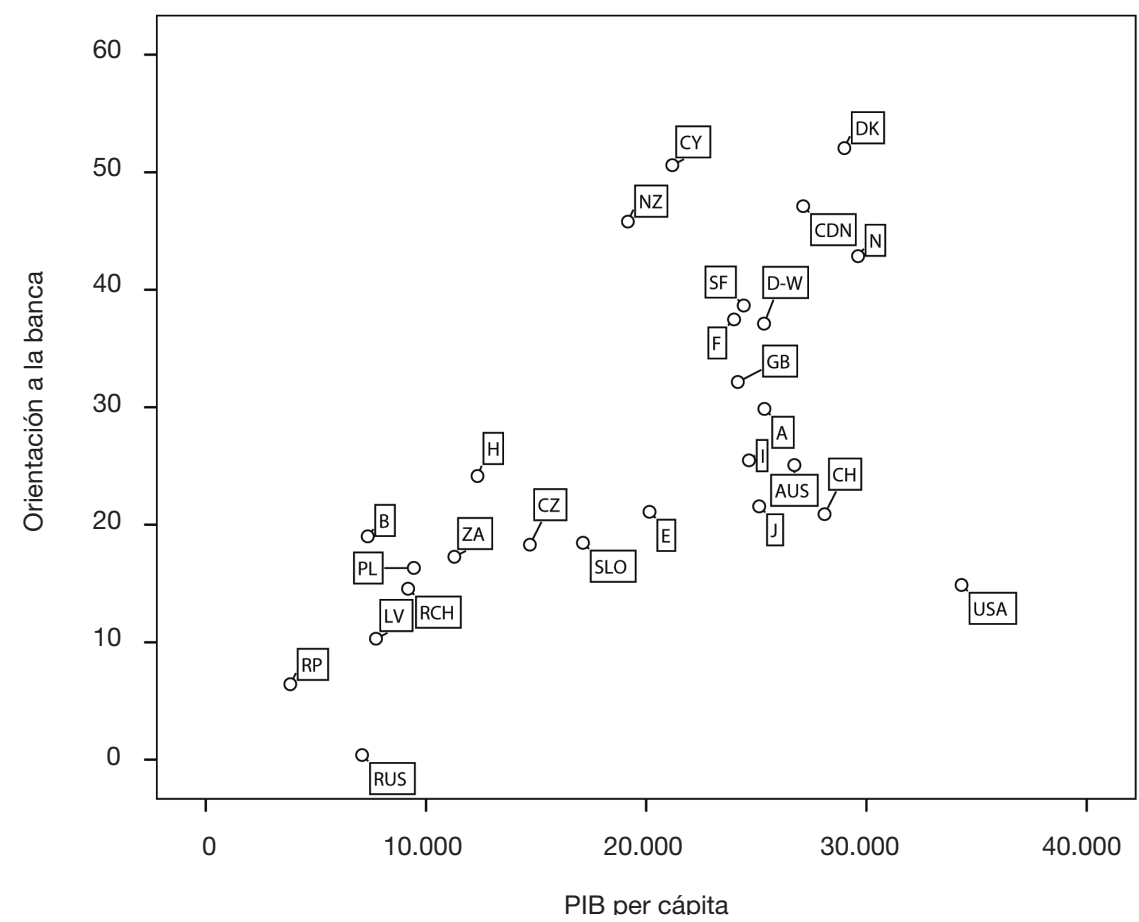

Fuente: elaboración propia.

en una reducción del peso porcentual de las orientaciones de proximidad, sobre todo las de proximidad no familiar, $y$, finalmente, del de aquellos que confiesan que no se lo pedirían a nadie.

Dentro del grupo de países más pobres, su presencia es muy baja, puesto que oscila entre un $0,4 \%$ en el caso de Rusia y cerca de un $25 \%$ en el de Hungría. En este intervalo, se sitúan países con una historia económica y política y una estructura social muy diferente, como Filipinas, Letonia, Eslovenia, Polonia, Brasil, Sudáfrica y la República Checa (figura 1).

En contraste con dichos países, entre los estados que sobresalen económicamente, el peso de esta orientación varía desde un 21,1\% para España o Japón a más del $50 \%$ en el caso de Dinamarca o de Chipre. Sorprende, debe de subrayarse, la posición que ocupa EE. UU., que tal vez pueda explicarse debido a la presencia de formas múltiples de contracción de deudas (por ejemplo: en comercios, áreas comerciales, etc.) que no son definidas socialmente como préstamos.

Además, variables fundamentales de la estructura social, como la edad, el género y el hecho de estar o no ocupado, influyen en las orientaciones hacia el préstamo y contribuyen a configurar las ESE de cada país. 
El análisis de varianza revela la presencia de un contraste estadísticamente significativo en función de la edad que refleja diferencias entre la franja más joven $(13,65)$ y los otros dos grupos de edad más maduros $(29,67$ de media) $(F=14,793, p<0,001)$. Más en detalle, entre los jóvenes (de 16 a 30 años), las diferencias según el nivel de desarrollo son poco apreciables, si bien debe destacarse que, dentro de esta franja y en algunos países muy desarrollados, se descubre una mayor inclinación hacia la banca en relación con el resto de otros países que supera el $20 \%$.

En estos países, la experiencia y el ejemplo de los mayores, que sirve como grupo de referencia para los más jóvenes, las estrategias de los bancos y el apoyo de los gobiernos a las prácticas de endeudamiento de los universitarios podrían contribuir a explicar, como apunta Bauman, esta mayor participación en el proceso de endeudamiento (Bauman, 2010: 61-64). Entrado el nuevo siglo y acompañando a la burbuja financiera, los jóvenes de los países más desarrollados han ocupado un lugar prioritario en las estrategias más recientes de captación de clientes.

En comparación con el segmento de población más joven, la orientación hacia la banca gana peso en el grupo de edad intermedio de los países más desarrollados y lo hace con más fuerza que en el mismo segmento de los menos desarrollados. Además, al analizar la diferencia entre países dentro de la franja más envejecida, se descubre una bifurcación en el comportamiento. En efecto, mientras que en los que van a la cabeza del desarrollo se observa un tímido progreso en este tercer grupo de edad, por el contrario, en los países económicamente rezagados, se reduce ligeramente su peso en relación con el segundo (figura 2). Mientras que, en los países cuyo PIB per cápita está situado por debajo de Eslovenia, la media se reduce en un 3,94\% (sobre una base comparativamente más baja), en los situados por encima se incrementa ligeramente (de un $35,90 \%$ a un $36,62 \%$ ).

En cuanto al género, los varones participan más que las mujeres de su propio país de esta disposición, pero, además, en el mundo más desarrollado, las diferencias a favor del hombre, y de un modo contraintuitivo, son mucho más pronunciadas (figura 3).

Finalmente, un factor que afecta a las distintas orientaciones es el hecho de estar ocupado (figura 4). En este caso, los coeficientes de correlación con la renta per cápita son significativos, puesto que alcanzan un 0,541 para los ocupados y un 0,628 para los no ocupados. En otros términos, la orientación hacia los bancos es más sensible al nivel de desarrollo entre los no ocupados que entre los ocupados. La población no ocupada de los países más ricos no parece estar tan alejada de los bancos, en contraste con la peor situación de los no ocupados respecto a los empleados de los países comparativamente más pobres. Estos datos referidos a la franja de edad intermedia revelan cómo, en todos los países sin excepción, tener una ocupación ejerce un efecto positivo sobre la inclinación hacia el grupo de referencia bancario. 
Figura 2. Orientación hacia la banca para cada segmento de edad y según el PIB per cápita de los países

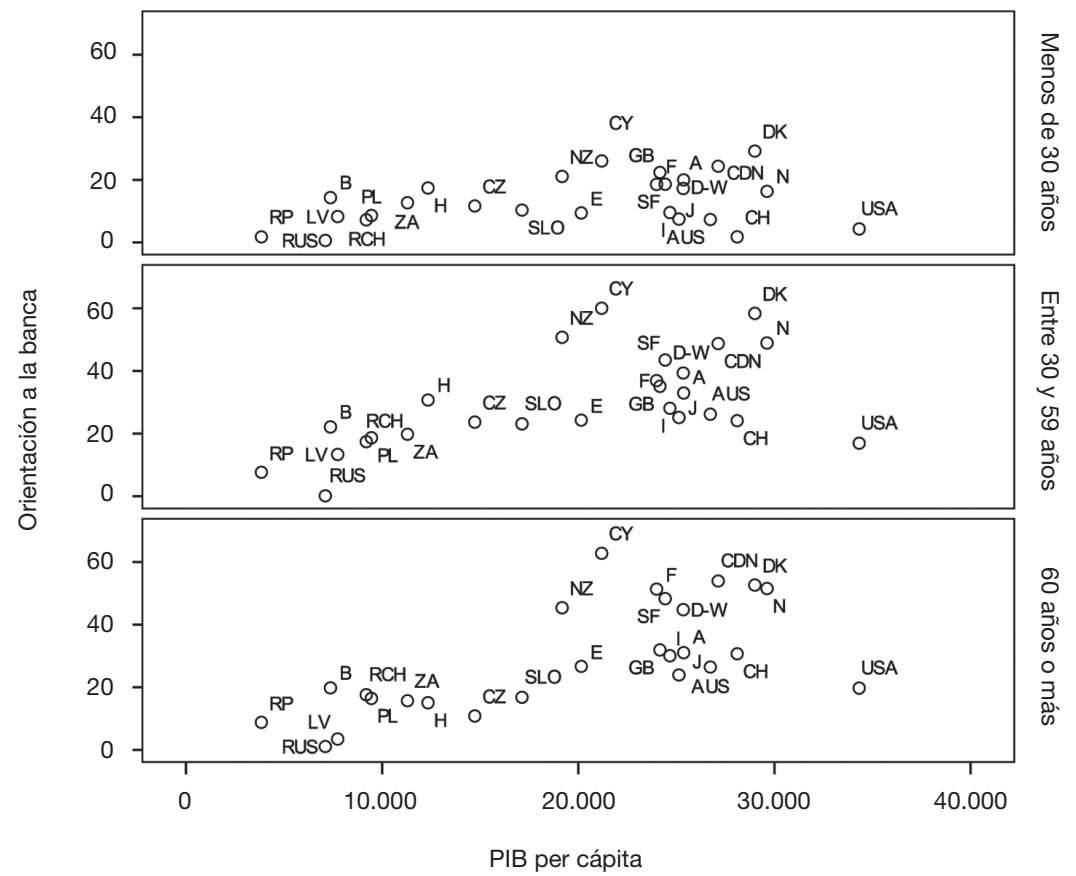

Fuente: elaboración propia.

Figura 3. Orientación hacia la banca según el PIB per cápita y para cada género

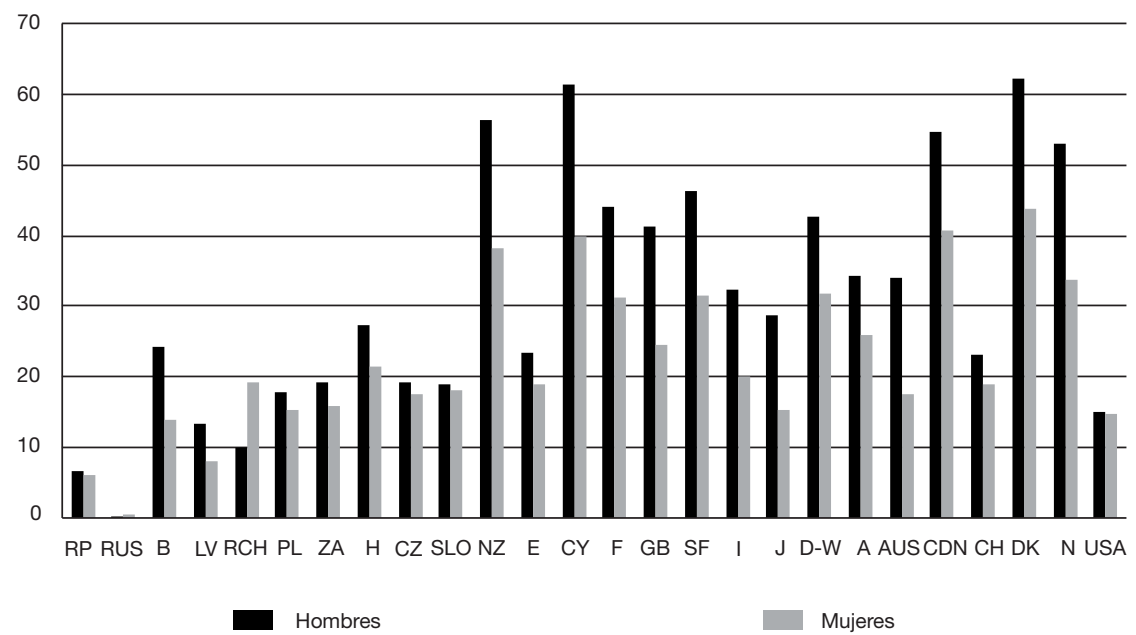

Fuente: elaboración propia. 
Figura 4. Orientación hacia la banca de los ocupados y de los no ocupados según el PIB per cápita y para el segmento intermedio de edad

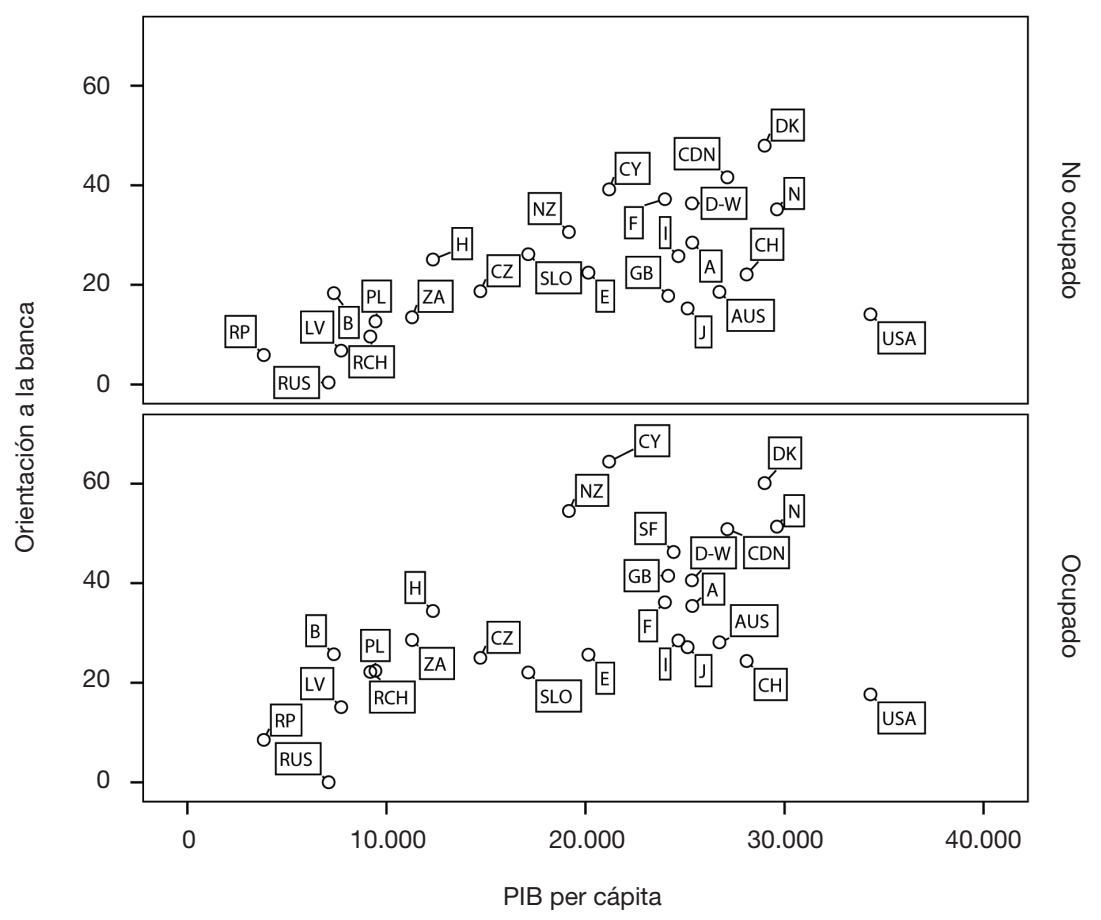

Fuente: elaboración propia.

\subsection{Las hipótesis relativas a las orientaciones de proximidad}

El análisis de la hipótesis 2 y de las dos proposiciones subordinadas (hipótesis 2.1 y 2.2) descubre pautas bien definidas en relación con el papel que desempeñan las diversas posiciones sociales dentro del círculo de proximidad familiar y no familiar.

Como ya apuntamos, las orientaciones hacia las posiciones de proximidad pierden peso con el desarrollo y lo hacen de un modo más pronunciado entre los varones que entre las mujeres. Pero, además, observando por separado las orientaciones familiares y extrafamiliares, el peso del conjunto de orientaciones hacia la familia es estadísticamente insensible al desarrollo, mientras las orientaciones hacia las posiciones situadas en la esfera de proximidad no familiar pierden peso a medida que se gana en desarrollo (tabla 4) y sin que se aprecien diferencias significativas según el género. En efecto, el conjunto de las orientaciones hacia las diversas posiciones familiares alcanza un coeficiente de correlación muy reducido de 0,019 no significativo. El análisis del clúster jerárquico presentado posteriormente (figura 6) nos permite comprender mejor esta falta de sensibilidad. Lo mismo sucede cuando se controla por el género, 
Tabla 4. Correlaciones entre el PIB per cápita y orientaciones

\begin{tabular}{lrrrrrrrrrr}
\hline & \multicolumn{10}{c}{ Orientaciones } \\
\cline { 2 - 11 } & Nadie & Banca & Pareja & PrNoFam & PrFam & \multicolumn{1}{c}{ Pr } & Desc & Lat & OtrFam & OtrAm \\
\hline Corr. & $-0,610$ & 0,621 & 0,604 & $-0,764$ & 0,019 & $-0,505$ & $-0,538$ & $-0,668$ & $-0,614$ & $-0,812$ \\
Sign. & 0,001 & 0,001 & 0,001 & $<0,001$ & 0,929 & 0,008 & 0,006 & $<0,001$ & 0,001 & $<0,001$ \\
\hline
\end{tabular}

Fuente: elaboración propia.

pero ocurre de un modo muy generalizado entre todos los países que esta inclinación al círculo familiar es más notoria en el caso femenino.

Sin embargo, y a pesar de la «escasa elasticidad» de estas orientaciones en relación con la renta per cápita, debe de subrayarse que, tanto la configuración interna del espacio de referencia familiar (hipótesis 2.1) como la del grupo de referencia no familiar (hipótesis 2.2), se trasforman profundamente con el desarrollo, de modo que el significado de estos espacios de proximidad parece variar con el nivel económico de los países.

Con el desarrollo económico, gana peso dentro del grupo de referencia familiar «la pareja» $\mathrm{y}$ «los ascendientes (el padre y la madre)», mientras que lo pierden el resto de posiciones del círculo familiar más extenso (tabla 5). En los países que se encuentran a la cola del desarrollo, las inclinaciones hacia posiciones dentro del universo parental son más heterogéneas y desempeña un papel más importante la familia extensa.

También se aprecian, como era de esperar, diferencias de género. El peso de las orientaciones hacia «la pareja» y hacia «los descendientes» en relación con el conjunto de posiciones familiares es mayor entre las mujeres que entre los hombres. En cambio, la inclinación hacia los ascendientes es mayor entre los hombres. Además, y en los tres casos, las diferencias se vuelven más pronunciadas a medida que se avanza en el desarrollo, tal y como se ilustra para el ratio de los descendientes dentro de la familia en la figura 5.

Siguiendo con el conjunto de la población y sin diferenciar por género: ¿qué podemos decir en relación con la dirección de las orientaciones en el universo de posiciones familiares?, ¿qué papel desempeñan los mayores en este campo de expectativas? El contraste entre países ofrece unas pautas bastante coherentes. Por regla general, en los países menos desarrollados y considerando la composición del conjunto de orientaciones hacia la familia, tienen más peso los mayores que esperan encontrar apoyo entre los descendientes (la mayor

Tabla 5. Correlaciones entre PIB per cápita y ratios de orientación familiar

\begin{tabular}{lccccc}
\hline & \multicolumn{5}{c}{ Ratio } \\
\cline { 2 - 6 } & P/Fam & Asc/Fam & Desc/Fam & Lat/Fam & Otr/Fam \\
\hline Corr. & 0,616 & 0,507 & $-0,640$ & $-0,777$ & $-0,638$ \\
Sign. & 0,001 & 0,010 & 0,001 & $<0,001$ & 0,001 \\
\hline
\end{tabular}

Fuente: elaboración propia. 
Figura 5. Ratio de los descendientes en la familia por sexo según el PIB per cápita

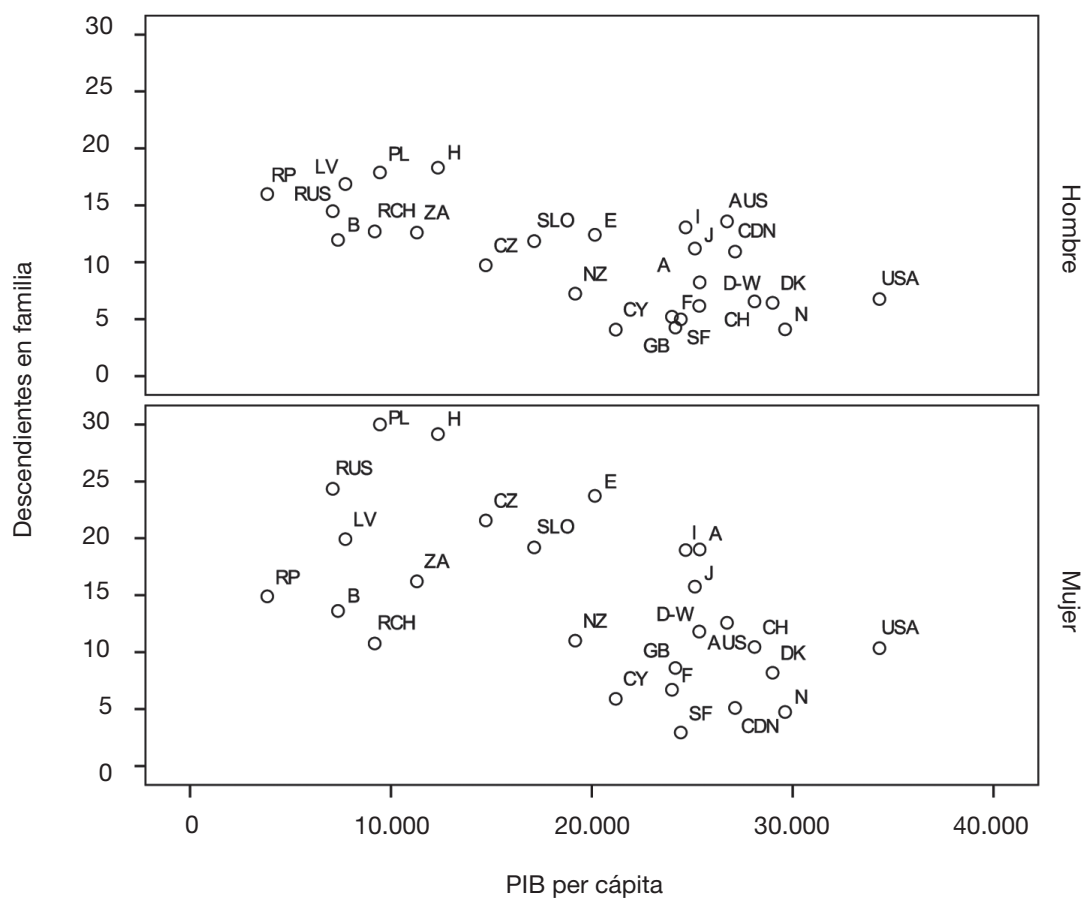

Fuente: elaboración propia.

parte de ellos, ligados al grupo de edad intermedia) que el que tienen los adultos de 30 a 60 años, que esperan encontrarlo entre los mayores.

Lo contrario sucede en los países más ricos. Estos se caracterizan por la presencia de una gran distancia entre el bajo peso de las orientaciones hacia los descendientes entre los más viejos y el elevado peso que adquieren las orientaciones hacia los ascendientes en el grupo intermedio (tabla 6).

Tabla 6. Correlaciones entre el PIB per cápita y ratios de orientación en familia según la edad

\begin{tabular}{llccccc}
\hline & & \multicolumn{5}{c}{ Ratios } \\
\cline { 3 - 7 } \multicolumn{1}{c}{ Edad } & & P/Fam & Asc/Fam & Desc/Fam & Lat/Fam & Otr/Fam \\
\hline Hasta 29 años & Corr. & 0,281 & 0,564 & $-0,469$ & $-0,801$ & $-0,581$ \\
& Sign. & 0,164 & 0,003 & 0,016 & $<0,001$ & 0,002 \\
\hline \multirow{2}{*}{ Entre 30 y 59 años } & Corr. & 0,569 & 0,557 & $-0,867$ & $-0,831$ & $-0,625$ \\
& Sign. & 0,002 & 0,003 & $<0,001$ & $<0,001$ & 0,001 \\
\hline Desde 60 años & Corr. & 0,673 & 0,182 & $-0,721$ & $-0,112$ & $-0,445$ \\
& Sign. & $<0,001$ & 0,374 & $<0,001$ & 0,234 & 0,023 \\
\hline
\end{tabular}

Fuente: elaboración propia. 
Por ejemplo, entre los países con un nivel de vida más elevado, el caso límite está representado por Francia, en donde un 30\% de los mayores se orientaría hacia sus hijos, mientras que un $55 \%$ de la franja de edad intermedia dice que pediría el préstamo a sus padres. El caso opuesto entre los países menos desarrollados se presenta en Polonia, con un 70\% de orientación hacia los descendientes en la franja de más edad frente a un $40 \%$ de orientación hacia los ascendientes entre el segmento de edad intermedio.

En esta línea, algunas investigaciones realizadas en Francia han puesto de relieve la importancia de la ayuda económica de los padres y ascendientes hacia los más jóvenes. Si, en otros tiempos - y aún hoy en las sociedades más pobres y que conservan estructuras sociales tradicionales-, las personas de edad más avanzada recibían ayuda de los más jóvenes y dependían de ellos, en la última década del siglo xx se descubre que una parte importante de este grupo tiene capacidad para mantenerse y ayudar a los más jóvenes. Factores como la extensión de los servicios públicos de bienestar, los sistemas de pensiones y la acumulación de un patrimonio a lo largo de la vida, en un contexto de fuerte crecimiento económico, podrían explicar la tendencia que se apunta hacia una inversión del sentido de esta relación de apoyo intergeneracional en relación con el préstamo, con lo cual se contribuye a la redefinición del rol de los mayores como fuente de apoyo económico (Attias-Donfut, 2000). Los resultados del análisis permiten sostener cómo este tipo de pauta observada en Francia está presente entre otros países, sobre todo en aquellos que van a la cabeza del desarrollo.

En relación con la hipótesis 2.2, las orientaciones de «proximidad extrafamiliar» no solo cobran mayor importancia en los países menos desarrollados, sino que también, y por añadidura, se vuelven más heterogéneas. En otras palabras, este conjunto incluye un mayor número de posiciones diferentes que se sitúan en las redes de proximidad no familiar (los amigos íntimos, los vecinos, los compañeros de trabajo y los jefes). Por el contrario, en los países muy desarrollados, son pocos los que se inclinan hacia estas posiciones no familiares, y los pocos que lo hacen recurrirían a un "amigo íntimo». En los países que lideran el desarrollo mundial, como Dinamarca, Nueva Zelanda, Gran Bretaña, Finlandia y Canadá, se sitúan entre un $1,58 \%$ y un 2,11\%, y en el caso de países latinos como España, Italia y Francia, este porcentaje aumenta ligeramente, sin llegar a superar en ningún momento los 4 puntos porcentuales, mientras que, en los países menos desarrollados, el peso más elevado se observa en Rusia, con un 29,36\%, seguido de Letonia, Sudáfrica, Filipinas, Chile y, finalmente, Brasil con un $12,82 \%$ (tabla 2).

Las correlaciones para el conjunto de los países confirman que las orientaciones hacia posiciones de proximidad son estadísticamente muy sensibles al nivel de desarrollo (tabla 4). Si del conjunto de orientaciones de proximidad eliminamos las orientaciones familiares, se descubre que la correlación con el PIB per cápita sigue siendo negativa y gana mucha fuerza explicativa. A medida que los países progresan económicamente, la reducción del papel 
Tabla 7. Correlaciones entre el PIB y variables según la ocupación de la población adulta madura

\begin{tabular}{|c|c|c|c|c|c|c|c|c|}
\hline & & \multicolumn{6}{|c|}{ Orientaciones } & \\
\hline & & Nadie & Banca & Pareja & PrNoFam & PrFam & $\mathrm{Pr}$ & \\
\hline \multirow[t]{2}{*}{ Ocup. } & Corr. & $-0,642$ & 0,997 & 0,409 & $-0,692$ & $-0,537$ & $-0,967$ & \\
\hline & Sign. & $<0,001$ & $<0,001$ & 0,038 & $<0,001$ & 0,005 & $<0,001$ & \\
\hline \multirow[t]{4}{*}{ No ocup. } & Corr. & $-0,583$ & 0,628 & 0,499 & $-0,757$ & 0,148 & $-0,423$ & \\
\hline & Sign. & 0,002 & 0,001 & 0,011 & $<0,001$ & 0,479 & 0,035 & \\
\hline & & \multicolumn{7}{|c|}{ Ratios } \\
\hline & & $\mathrm{Fam} / \mathrm{Pr}$ & P/Fam & Asc/Fam & Desc/Fam & Lat/Fam & Otr/Fam & Int/NoFam \\
\hline \multirow[t]{2}{*}{ Ocup. } & Corr. & 0,781 & 0,587 & 0,530 & $-0,894$ & $-0,844$ & $-0,640$ & 0,459 \\
\hline & Sign. & $<0,001$ & 0,002 & 0,005 & $<0,001$ & $<0,001$ & $<0,001$ & 0,018 \\
\hline \multirow[t]{2}{*}{ No ocup. } & Corr. & 0,746 & 0,535 & 0,375 & $-0,644$ & $-0,673$ & $-0,685$ & 0,713 \\
\hline & Sign. & $<0,001$ & 0,006 & 0,065 & 0,001 & $<0,001$ & $<0,001$ & $<0,001$ \\
\hline
\end{tabular}

Fuente: elaboración propia.

desempeñado por las orientaciones de proximidad no familiar es mucho más fuerte que la reducción que se observa para el conjunto de las orientaciones de proximidad. Además, si dentro de este último tipo, consideramos tan solo las orientaciones hacia los que "no son amigos íntimos» (conocidos, vecinos, compañeros de trabajo y jefes), el efecto de este cambio es más acusado.

Finalmente, conviene detenerse en el comportamiento de los ocupados frente a los no ocupados del segmento de edad intermedia. El peso de las orientaciones de proximidad en los países menos desarrollados no ofrece diferencias entre ocupados y no ocupados; sin embargo, pierden peso en los países más desarrollados, descenso que se manifiesta con más fuerza en los países que ofrecen una orientación muy marcada hacia la banca (tabla 3).

Además, los ocupados se inclinan algo menos hacia la familia y muestran una mayor propensión, sobre todo en los países menos desarrollados, hacia el grupo de referencia no familiar. En el espacio de relaciones sociales «no familiares», los que tienen una ocupación disponen de la oportunidad de orientarse hacia los compañeros de trabajo y los jefes, y lo hacen así en casi todos los países, pero sobre todo en los de menor PIB per cápita (tabla 7). Esto revela la importancia que puede tener en algunas zonas la estructura social de proximidad laboral, que, de un modo latente, condiciona las oportunidades disponibles para pedir un préstamo (figura 6 ).

En consecuencia, muchas de las posiciones que son imaginables en los países menos desarrollados no lo son entre los países más ricos. Lo mismo podría decirse en relación con las orientaciones hacia la banca y las entidades financieras en los países comparativamente más pobres. En su caso, tampoco se imaginan esta posibilidad, no se sitúa en su horizonte cognitivo o simplemente se renuncia a ella. 
Figura 6. Ratio de íntimos en relaciones no familiares según la ocupación

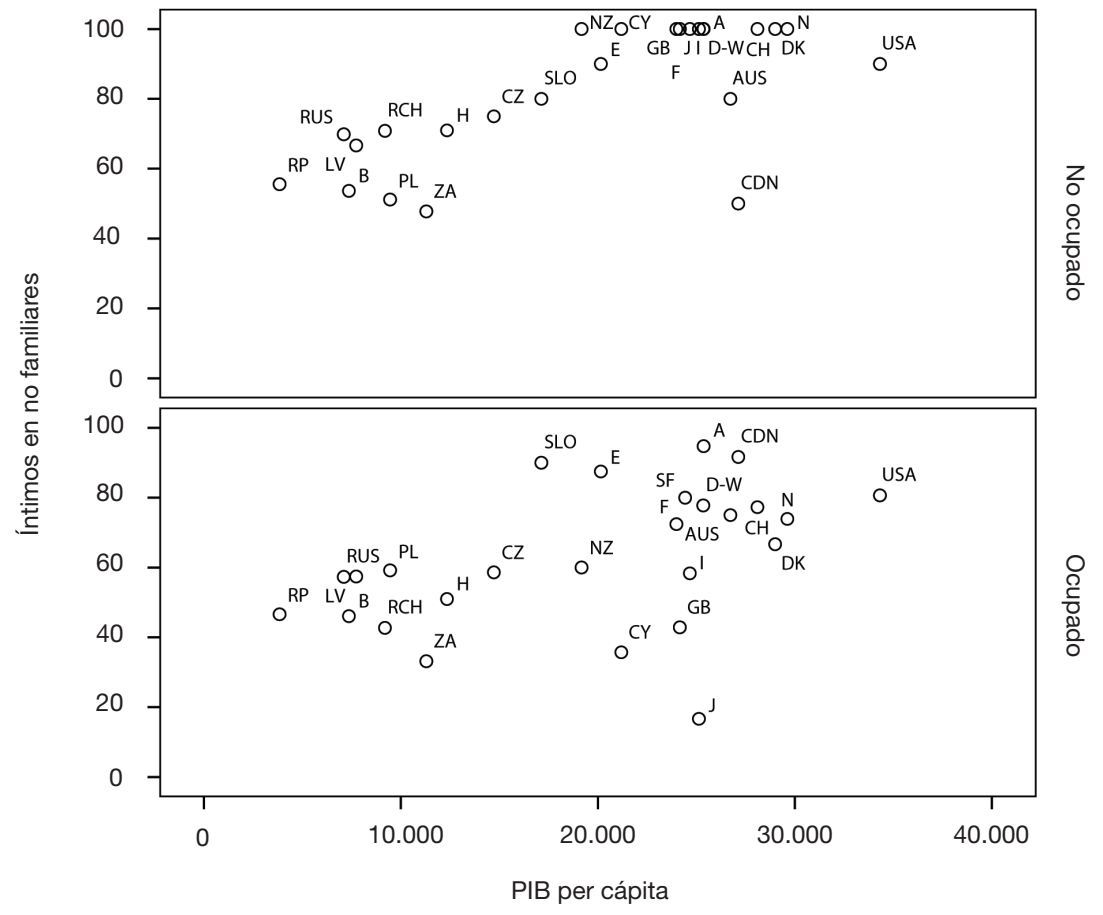

Fuente: elaboración propia.

\subsection{La exclusión de las redes de préstamo}

El peso de las orientaciones hacia las estructuras de proximidad en los países con menos desarrollo no constituye una salvaguarda frente a las situaciones de exclusión asociadas a la pobreza. En términos generales, se puede concluir que la probabilidad de responder que «no se lo pedirían a nadie» se incrementa entre los países más pobres, entre los que carecen de ocupación - y presumiblemente son menos solventes- y entre aquellos tramos de edad que superan los sesenta años (figura 7). En estos países, y sobre todo para las personas mayores, se reducen notablemente los recursos sociales y financieros.

Esto significa que, en los países menos desarrollados, una parte importante de esta población carece de un referente, ya sea una persona, un grupo social o un banco al que poder recurrir en caso de tener que solicitar una gran cantidad de dinero. Es posible que el riesgo de exclusión social y financiera y las secuelas y los efectos de la pobreza se retroalimenten. Tampoco debería de descartarse, entre otros motivos, la presencia de una cultura contraria al endeudamiento que podría ser más severa entre las personas de más edad 
Figura 7. Orientación hacia nadie por edades según PIB per cápita

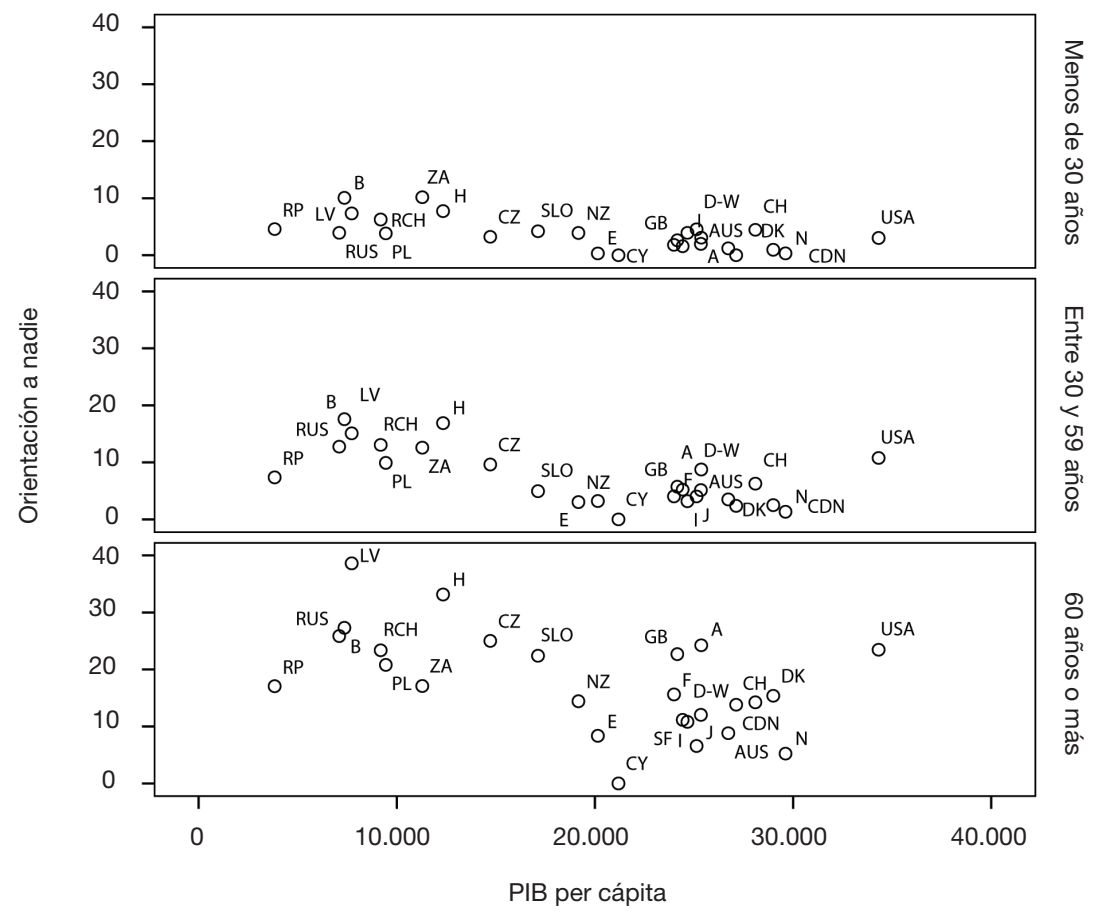

Fuente: elaboración propia.

de los países menos desarrollados, como se sugería hace años en un ensayo sobre las orientaciones hacia la deuda en Argelia (Bourdieu et al., 1964; Swedberg, 2010).

Finalmente y teniendo de nuevo en cuenta la variable ocupado / no ocupado, son los ocupados, con mayor probabilidad de ser solventes o de estar integrados socialmente, los que con menos frecuencia señalan que «no se lo pedirían a nadie».

Entre los no ocupados, esos porcentajes, y para el segmento de edad intermedia, el peso de esta orientación aumenta hasta el punto de que, en países desarrollados como EE. UU., las orientaciones de los no ocupados y de los ocupados alcanzan, respectivamente y como media, un $14,07 \%$ y un $9,90 \%$, frente a Noruega, que registra los niveles más bajos, con un 2,76\% y un 0,95\%, respectivamente. Entre los países menos desarrollados, se podría destacar Hungría, con un $24,15 \%$ y un $12,5 \%$. En consecuencia, no solo los ocupados se orientan más hacia los bancos, sino que también se orientan menos hacia la familia, más a las posiciones extrafamiliares, sobre todo en los países menos desarrollados, y son ellos los que, con menor frecuencia, confiesan que no se lo pedirían a nadie. 


\section{Un análisis jerárquico de la estructura social de endeudamiento: contexto social, económico e institucional}

Hasta el momento, se ha observado la presencia de algunas relaciones concomitantes entre el nivel de desarrollo económico, el tipo de orientaciones hacia el préstamo y las diferencias en el modo en que se configuran diversas figuras familiares y extrafamiliares que se adoptan como referencia. A partir de las variables analizadas, excluyendo la orientación de proximidad por ser agregación directa de otras, interesa también verificar si existen grupos de países con una identidad definida, tanto en relación con el peso de las variables de primer orden (orientaciones) como de las variables de segundo orden (ratios).

Con este propósito, se ha realizado un análisis de conglomerados jerárquico. Se emplearon distintas metodologías de agrupación y distancias para comparar la estabilidad de la solución propuesta. El número de grupos fue seleccionado en base al dendograma y a los cambios en el coeficiente de aglomeración. La solución propuesta fue validada posteriormente mediante la realización de un análisis no jerárquico K-medias con tres grupos sin centros iniciales y comprobando la significación de las diferencias de medias entre los grupos propuestos. Los resultados de la solución jerárquica, aplicando el método de Ward, permite definir tres grupos. En la tabla 8, se presentan los resúmenes descriptivos (media y desviación típica) para cada una de las variables estudiadas en esos tres grupos.

El grupo A, formado por los países que denominaremos «ricos bancarizados», incluye Gran Bretaña, Alemania, Austria, Noruega, Nueva Zelanda, Canadá, Francia, Chipre, Dinamarca y Finlandia. En todos ellos, la banca ocupa un lugar muy relevante en comparación con los otros dos grupos.

En el grupo B, se incorpora un conjunto de estados que calificamos de «ricos familistas» y está formado por Australia, EE. UU., Italia, República Checa, Eslovenia, Japón, España y Suiza. Presentan rentas per cápita elevadas, donde tienen una gran importancia las referencias a posiciones en el círculo familiar $\mathrm{y}$, a diferencia del grupo A de ricos bancarizados, su composición es internamente más diversificada. Las orientaciones hacia el círculo de referencia familiar triplican el peso de las orientaciones hacia el horizonte bancario de referencia y constituye la agrupación de países con un mayor peso de las orientaciones familiares. Algunos de estos países, como España, Italia y Japón, se reconocen, a pesar de las transformaciones que han tenido lugar durante las últimas tres décadas, como familistas en la tradición de la literatura sociológica. En el caso de EE. UU., es posible que el cuestionario no detecte otras formas «latentes» de endeudamiento, motivo por el que se sitúa en este grupo. Cabe pensar también en la importante presencia de minorías étnicas sin acceso al crédito formal.

Finalmente, el grupo C, que calificamos de «emergentes comunitarios», incluye países como Hungría, Polonia, Rusia, República Filipina, Letonia, República de Chile, Brasil y Sudáfrica. Está formado por un conjunto de países que, por término medio, presentan un menor peso de la banca y en los que las orientaciones hacia posiciones situadas en la estructura de proximidad (familiar 
Tabla 8. Medias (desviaciones típicas) en la solución jerárquica

\begin{tabular}{|c|c|c|c|c|c|c|c|}
\hline \multirow{2}{*}{ Orientaciones } & \multirow[b]{2}{*}{ Banca } & \multicolumn{2}{|c|}{ Grupo A } & \multicolumn{2}{|c|}{ Grupo B } & \multirow{2}{*}{$\frac{\text { Grupo C }}{13,55(7,55)}$} & \multirow{2}{*}{$\begin{array}{c}\text { Todos } \\
26,46(13,88)\end{array}$} \\
\hline & & 41,37 & $(7,54)$ & 20,72 & $(3,54)$ & & \\
\hline & Fam & 49,76 & $(5,06)$ & 65,33 & $(3,74)$ & $55,18(7,82)$ & $56,22 \quad(8,59)$ \\
\hline & NoFam & 2,58 & $(0,95)$ & 5,85 & $(3,34)$ & $16,72(7,59)$ & $7,94 \quad(7,56)$ \\
\hline & Nadie & 5,92 & $(3,36)$ & 7,45 & $(2,91)$ & $14,06(3,56)$ & $8,89 \quad(4,76)$ \\
\hline & Prox & 52,34 & $(5,44)$ & 71,18 & $(2,16)$ & $71,90(9,51)$ & $64,16(11,32)$ \\
\hline \multirow[t]{7}{*}{ Ratios } & Fam/Prox & 95,12 & $(1,62)$ & 91,79 & $(4,66)$ & $77,15(8,90)$ & $88,57 \quad(9,56)$ \\
\hline & Par/Fam & 39,59 & $(6,45)$ & 27,87 & $(13,24)$ & $15,20(5,68)$ & $28,48(13,38)$ \\
\hline & Asc/Fam & 40,12 & $(4,14)$ & 38,84 & $(9,63)$ & $32,13 \quad(4,54)$ & $37,27 \quad(7,10)$ \\
\hline & Desc/Fam & 7,47 & $(3,04)$ & 13,95 & $(3,72)$ & $17,87 \quad(5,03)$ & $12,66 \quad(5,85)$ \\
\hline & Later/Fam & 7,64 & $(2,22)$ & 12,48 & $(3,15)$ & $19,95(4,05)$ & $12,92 \quad(6,01)$ \\
\hline & OtrFam/Fam & 5,18 & $(1,84)$ & 6,86 & $(4,50)$ & $14,86(3,88)$ & $8,68 \quad(5,41)$ \\
\hline & Int/NoFam & 79,47 & $(10,25)$ & 74,46 & $(11,26)$ & $54,09(7,64)$ & $70,12(14,59)$ \\
\hline
\end{tabular}

Fuente: elaboración propia.

y extrafamiliar) es mayor. Además, la heterogeneidad de las posiciones, tanto en el círculo de referencia familiar como extrafamiliar, es más acusada que en los otros dos grupos. Se corresponden con estados que disponen de una renta per cápita baja, y cuatro de ellos, como es el caso de Filipinas, Brasil, Rusia y Sudáfrica, muestran grandes dimensiones en términos de población y están calificados con un IDH de tipo medio.

Más en detalle, y en relación con el peso de las orientaciones de proximidad, el grupo B (rico familista) y el grupo C (de países emergentes comunitarios), con una media de un $71,18 \%$ y un $71,90 \%$ respectivamente, se sitúan nítidamente por encima del grupo A (de ricos bancarizados), con una media de un $52,34 \%$.

Destaca el peso de las orientaciones hacia la familia del grupo rico familista, que ofrece la media más elevada (un 65,33\%), seguido del grupo de países emergentes comunitarios y, finalmente, del grupo de ricos bancarizados (un $49,76 \%)$. En cuanto a las orientaciones de proximidad no familiar, el peso mayor corresponde al grupo $\mathrm{C}$ (emergente comunitario), con un $16,72 \%$ frente a un $5,85 \%$ del grupo $\mathrm{B}$ y un $2,58 \%$ del grupo $\mathrm{A}$.

Las orientaciones extrafamiliares tienen algo más de peso dentro de las orientaciones de proximidad en el grupo B (rico familista) que en el grupo A. Al compararse con el grupo $\mathrm{C}$ (países emergentes comunitarios), el peso es sensiblemente menor (tabla 8).

Si se observa el gráfico de la figura 8, en los dos grupos más ricos, el familista y el bancarizado, se aprecia un apiñamiento en el eje de ordenadas, mientras que, en el grupo C, la dispersión de las orientaciones familiares se acompaña de un elevado peso de las posiciones extrafamiliares en el conjunto de las orientaciones de proximidad.

La composición interna de las orientaciones hacia posiciones familiares que, en el grupo A, está muy concentrada en torno a los ascendientes y la pareja, 
Figura 8. Ratio de familia en proximidad según la orientación a la familia con solución jerárquica

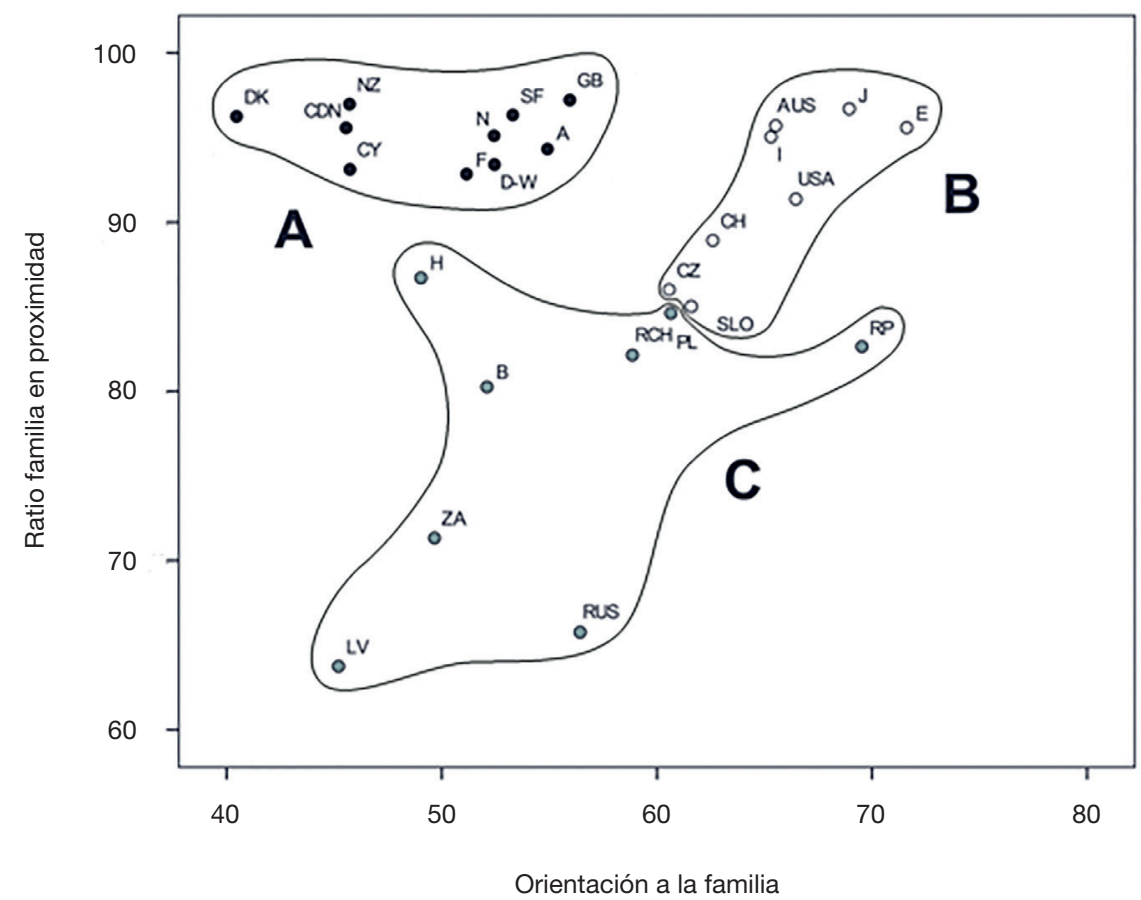

Fuente: elaboración propia.

se diversifica hacia otras posiciones (descendientes, laterales, otros familiares) y se vuelve aún más heterogénea en el caso del grupo de países emergentes comunitarios (tabla 8).

Por ejemplo, en el grupo B, de países ricos familistas, el ratio de ascendientes en familia tiene mucho peso, como también sucede en el grupo A, de ricos bancarizados. Pero, en comparación con este último, en el grupo B, pierde peso el ratio de pareja en familia y lo ganan los otros ratios relativos al resto de posiciones referidas a un círculo familiar más extenso, con lo que se aproximan al perfil más heterogéneo que caracteriza a las orientaciones del grupo C. En este último, se reduce la desigualdad entre los ratios correspondientes a las posiciones de ascendientes, pareja, descendientes, laterales y otros familiares.

Las orientaciones hacia posiciones no familiares tienen un escaso peso en el grupo A y en el B de países ricos en comparación con el C (un 16,72\%). De nuevo y de un modo parecido a lo que sucede en relación con la familia, este grupo $\mathrm{C}$ muestra una composición sensiblemente más diversificada entre conocidos, vecinos, compañeros de trabajo y jefes.

Aunque la agrupación presentada permite observar de qué modo se configuran los países analizados en función de las diversas orientaciones y ratios 
empleados en el análisis, además de aproximarnos a la representación social de la ESE, es conveniente determinar si estos grupos encuentran un anclaje razonable en la estructura social. Por este motivo, presentamos algunas de las características que afectan tanto al orden económico, financiero e institucional como a la estructura familiar de cada uno de los países. En este análisis, se debe tener en cuenta que se trata de reflejar el contexto en el que se desarrollan las diversas orientaciones del endeudamiento y no tanto hacer corresponder la agrupación presentada con un determinado modelo de realidad socioeconómica.

De esta manera, podemos observar la existencia de una coherencia razonable, por un lado, entre el peso de las orientaciones de proximidad y los rasgos que predominan en relación con la estructura familiar y comunitaria, y, por otro, entre la orientación bancaria y las oportunidades que ofrece la situación económico-financiera, así como las características del sistema económico de cada país. En la tabla 9, se presentan, para los países estudiados, algunos indicadores que se han seleccionado para caracterizar estos hechos socioeconómicos.

En relación con la situación económico-financiera e institucional de cada colectivo, los países incluidos en los grupos A y B del estudio son más homogéneos, ocupan una situación sólida y responden, con alguna excepción, a órdenes económicos e institucionales relativamente estables.

El grado de «atractivo" $\mathrm{y}$ "confianza» que se deposita en un país para obtener financiación externa se asocia al índice de clasificación de riesgo compuesto y a la clasificación crediticia. Estos indicadores, elaborados en función de la situación social, política y económica, son utilizados como criterio de evaluación por los actores económicos y políticos globales (Banco Mundial, 2001). Los valores de estos datos en los países ricos (familistas o bancarizados) son altos (en general, superiores a 80), lo que revela que muestran un bajo riesgo para la inversión y una baja probabilidad de impago de su deuda. Todos ellos son factores decisivos para atraer la inversión externa y disponer de un flujo de capital privado. Este contexto puede explicar el hecho de que la orientación bancaria en estos países sea elevada en contraposición al grupo C. Análogamente, salvo alguna excepción, se registra el mismo comportamiento al analizar el peso que tiene el crédito interno suministrado al sector privado por los bancos en relación con el tamaño de la economía de los países y el tipo de interés activo que cobran los bancos por los préstamos, datos que reflejan el peso del crédito dentro de la economía de cada país y la mayor o menor facilidad de acceso al préstamo en el sistema financiero formal.

Aunque es cierto que la oferta de crédito y el precio del dinero están asociados a las políticas monetarias y a las variables presentadas, la demanda de crédito está condicionada por la situación económica y por factores de la estructura socioeconómica, como el régimen de bienestar o el grado de desigualdad interna del país. Es razonable pensar que, en países de elevados ingresos y bajos niveles de desigualdad, se facilita el acceso al crédito, mejora la calificación crediticia del solicitante, se reduce la necesidad de acudir a un crédito ante situaciones imprevistas (emergencias, problemas de salud, etc.) y disminuye la tasa de morosidad, así como los riesgos de sobreendeudamiento y de impago. 
Tabla 9. Número de miembros por hogar privado, 2001, (2) Porcentaje, 2007, (3) Hijos por mujer, 2001, (4) 2000, (5) Porcentaje del PIB, 2001, (6) 2000, (7) Porcentaje, 2001.

\begin{tabular}{|c|c|c|c|c|c|c|c|c|c|c|}
\hline País & Grupo & $\begin{array}{l}\text { Tamaño } \\
\text { medio } \\
\text { hogar } \\
(1)\end{array}$ & $\begin{array}{c}\text { Niños en hogares } \\
\text { multigeneracionales } \\
\text { (3) }\end{array}$ & $\begin{array}{c}\text { Tasa } \\
\text { fertilidad } \\
\text { total (3) }\end{array}$ & $\begin{array}{c}\text { Clasificación } \\
\text { del riesgo } \\
\text { compuesto } \\
\text { según la ICRG (4) }\end{array}$ & $\begin{array}{c}\text { Clasificación } \\
\text { crediticia de } \\
\text { Institutional } \\
\text { Investor (4) }\end{array}$ & $\begin{array}{c}\text { Crédito interno } \\
\text { suministrado } \\
\text { por el sector } \\
\text { bancario (5) }\end{array}$ & $\begin{array}{c}\text { Diferencial } \\
\text { de tasas } \\
\text { de interés } \\
\text { (6) }\end{array}$ & $\begin{array}{c}\text { Tasa de } \\
\text { interés } \\
\text { activa } \\
\text { (7) }\end{array}$ & $\begin{array}{l}\text { Índice } \\
\text { de Gini } \\
\text { (6) }\end{array}$ \\
\hline Noruega & A & 2,3 & & 1,8 & 89,5 & 89,3 & 68,7 & 2,3 & 8,7 & 25,8 \\
\hline Dinamarca & A & 2,2 & 0,4 & 1,7 & 86 & 86,3 & 138,7 & 4,9 & 8,2 & 24,7 \\
\hline Canadá & A & 2,7 & & 1,5 & 85 & 85,1 & 122,4 & 3,6 & 5,8 & 31,6 \\
\hline Austria & A & 2,5 & 7,5 & 1,3 & 82 & 89 & 109,9 & & & 23,1 \\
\hline Alemania & A & 2,1 & 0,9 & 1,4 & 83,3 & 92,9 & 136,1 & 6,5 & 10,0 & 30,0 \\
\hline Finlandia & A & 2,2 & 0,6 & 1,7 & 88,8 & 85,6 & 55,8 & 3,8 & 5,8 & 25,6 \\
\hline Gran Bretaña & A & 2,4 & 3,4 & 1,6 & 83,3 & 91,1 & 128,2 & & 5,1 & 36,1 \\
\hline Francia & A & 2,3 & 1,8 & 1,9 & 80,3 & 91,7 & 92,8 & 4,0 & 7,0 & 32,7 \\
\hline Chipre & A & & 3,0 & 1,7 & & & 155,3 & 1,8 & 7,5 & \\
\hline Nueva Zelanda & A & 2,6 & & 2,0 & 75,5 & 80,3 & 106,7 & 2,2 & 7,6 & 43,9 \\
\hline Estados Unidos & B & 2,6 & & 2,0 & 80 & 92,9 & 50 & & 6,9 & 40,8 \\
\hline Suiza & B & 2,2 & & 1,4 & 76,3 & 59,1 & 140,6 & 2,6 & 4,3 & 25,4 \\
\hline Australia & B & 2,6 & & 1,7 & 82 & 89,4 & 88,6 & 4,8 & 8,7 & 35,2 \\
\hline Japón & B & 2,7 & & 1,3 & 82 & 86,9 & 111,1 & 1,9 & 2,0 & 24,9 \\
\hline Italia & B & 2,6 & 5,0 & 1,3 & 79,5 & 82 & 77,4 & 5,3 & 7,3 & 27,3 \\
\hline España & B & 3,0 & 5,8 & 1,2 & 75,8 & 80,4 & 103,7 & 2,1 & 5,2 & 32,5 \\
\hline Eslovenia & B & & 13,7 & 1,2 & 79,8 & 63,1 & 37,2 & 5,2 & 15,1 & 26,8 \\
\hline Rep. Checa & B & 2,6 & 7,7 & 1,2 & 88,3 & 93,8 & 35,8 & 4,3 & 7,2 & 33,1 \\
\hline Hungría & C & 2,6 & 11,6 & 1,3 & 74,3 & 59,2 & 32,7 & 3,7 & 12,1 & 30,8 \\
\hline Sudáfrica & C & 3,8 & & 2,8 & 70,5 & 45,2 & 74,4 & 4,4 & 13,8 & 59,3 \\
\hline Polonia & C & 2,9 & 22,0 & 1,3 & 76,0 & 58,0 & 27,3 & 6,6 & 18,4 & 32,9 \\
\hline Chile & C & 3,9 & & 2,0 & 74,5 & 62,6 & 62,2 & 5,7 & 11,9 & 56,5 \\
\hline Letonia & C & & 24,4 & 1,2 & 72,3 & 43,4 & 26,2 & 5,9 & 11,2 & 32,4 \\
\hline Brasil & C & 3,8 & & 2,3 & 64,8 & 38,5 & 29,0 & 39,8 & 57,6 & 60,0 \\
\hline Rusia & C & 2,7 & & 1,3 & 54,8 & 19,6 & 16,8 & 13,1 & 17,9 & 48,7 \\
\hline Rep. Filipinas & C & 4,9 & & 3,8 & 70,8 & 46,7 & 37,5 & 3,7 & 12,4 & 46,2 \\
\hline
\end{tabular}

Fuente: elaboración propia.

Los países con un régimen de bienestar de tipo socialdemócrata, según la tipología de Esping-Andersen (2000), como Noruega, Dinamarca y Finlandia, con altos ingresos y coeficientes de Gini bajos, son los que ofrecen mayores niveles de orientación hacia la banca y un menor riesgo de exclusión financiera. Estos países se concentran en el grupo A, a diferencia de otros que se caracterizan por un régimen de bienestar de tipo liberal con coeficientes de Gini más elevados o con un régimen conservador familiarista (con valores intermedios en el coeficiente de Gini) y que se encuentran presentes tanto en el grupo A como en el grupo B. Según esta tipología, se incluyen, entre los países de régimen liberal, Reino Unido, Nueva Zelanda, Australia y EE. UU., mientras que, entre los de régimen de bienestar de tipo conservador familiarista, encontramos a Francia, Austria, Italia o España. 
Si bien, en los países desarrollados, la desigualdad interna no está necesariamente relacionada con el peso del sector financiero (Philippon y Reshef, 2013), en los países de mayor nivel de desigualdad, que mayoritariamente están en el grupo C, la incertidumbre de los mercados financieros y los altos tipos de interés pueden dificultar el acceso al crédito por parte de amplios sectores de la población con rentas bajas.

Este grupo de países emergentes comparte un contexto de fuerte «incertidumbre» económica e institucional y viven en un entorno de una elevada inestabilidad financiera internacional en los años anteriores a la encuesta ISSP 2001. La quiebra política y económica de la URSS y las turbulencias económico-financieras de Brasil pueden ser dos ejemplos ilustrativos de esta fragilidad. En los países del Este de Europa y en Rusia, el crédito al consumo comienza a introducirse a finales de la década de 1990, mientras que, en el caso de Brasil (como también de Filipinas, Sudáfrica y Chile), este producto financiero existía, pero era muy caro y al alcance tan solo de una minoría.

La introducción del sistema de libre mercado en la Europa del Este se traduce, a principios de la década de 1990, en una brusca caída del PIB, que se manifiesta en la quiebra de grandes empresas y en una fuerte disminución del empleo y de los salarios (King y Szelényi, 2005; Rona-Tas y Guseva, 2014). Las políticas de ajuste estructural y la creación de un nuevo marco institucional acorde con las exigencias de una economía de mercado se acompaña de la creación de bancos privados que, finalmente, serán adquiridos por entidades financieras internacionales. La dificultad y la resistencia a la penetración del mercado de crédito se explica igualmente por la escasa disposición y experiencia de la gente en relación con el endeudamiento. En este sentido, apuntan Rona-Tas y Guseva que «los países poscomunistas tenían poca experiencia en la banca minorista en general y en los créditos de consumo en particular, y la gente no estaba convencida acerca del interés de endeudarse para pagar los bienes de consumo» (Rona-Tas y Guseva, 2014: 92). Sin embargo, a principios del siglo XxI, y a juzgar por la tímida presencia de la banca en las orientaciones de la población de Hungría y Polonia, estas prácticas comienzan a incorporarse a la vida cotidiana de algunos segmentos de la población (tabla 3).

La situación de la Federación Rusa fue sensiblemente peor que la vivida por los países de la Europa del Este, pues la introducción del libre mercado en Rusia se hizo, además, sin una adecuada transformación del marco institucional, en contraste con la sincronización que se consiguió en el resto de los países del Este, sobre todo en Hungría y Polonia (Stiglitz, 2002). En Rusia, el PIB cae en un $40 \%$ durante esta década y el colapso de la economía se traduce en un fuerte aumento de la pobreza y de la desigualdad (el índice de Gini se sitúa en un $48,7 \%$ en 2001). La huida de capitales y la caída de los precios del petróleo en 1998 hacen que Rusia declare el impago de su deuda y el FMI intervenga en su rescate, ante el riego sistémico que supone la bancarrota de este país. En dicho escenario, no llega a desarrollarse una sólida red bancaria y el precio del dinero es elevado, de modo que es comprensible que la orientación hacia la banca no supere el $0,5 \%$ (tabla 3 ). 
Brasil se sitúa en un orden social y económico diferente. Ocupando una posición estratégica en el continente latinoamericano y en un contexto de acusada inestabilidad de los mercados financieros, en la década de 1990, se enfrentó a fuertes desequilibrios, tensiones provocadas por una deuda pública creciente, movimientos especulativos frente a su moneda, así como a unas elevadas tasas de inflación. Las políticas de ajustes estructurales se acompañaron de políticas monetarias y presupuestarias muy restrictivas (Sand-Zantman, 2005). En el terreno del sector financiero, se asistió a un proceso de desnacionalización de la banca privada que en buena parte fue adquirida por grandes corporaciones extranjeras (Guillén y Tschoegl, 2000). El resto de los países de este grupo (Sudáfrica, Chile y Filipinas), aunque mantenían un crecimiento sostenido en los años noventa, no consiguieron evitar los efectos del entorno turbulento que se derivó de la crisis financiera del Sudeste Asiático iniciada en 1997 en Tailandia. En este contexto, el crédito era caro y el sistema crediticio débil, lo que acompañado del nivel de desigualdad interna existente entre la población y las estructuras sociales tradicionales, explicaría el elevado grado de exclusión financiera y la orientación hacia redes comunitarias familiares y extrafamiliares.

Las orientaciones hacia las estructuras familiares y comunitarias presentan una correspondencia razonable con los indicadores relativos a la familia que se muestran en la tabla 9. Los países del grupo A (ricos bancarizados) ofrecen una estructura del hogar (por lo que se refiere al tamaño) de naturaleza más nuclear que los países del grupo B, con un círculo familiar algo más extenso. Sin embargo, el salto más pronunciado se produce entre estos dos grupos y el grupo C (emergentes comunitarios), en el que se presentan los valores más altos en relación con diversas características familiares y comunitarias, como el tamaño del hogar, el procentaje de hijos en domicilios multigeneracionales o la tasa de fecundidad total, lo que les permitiría activar más lazos o recursos parentales y/o comunitarios.

Esto parece indicar que, cuando el mercado de crédito «no existe» o la oferta de crédito es limitada, el precio del dinero es elevado y la población es calificada como insolvente, la orientación dominante consistirá en una retirada a las ESE de proximidad.

\section{A modo de conclusión}

En esta investigación, se aborda una reflexión sociológica, teórica y empíricamente fundada, sobre el lugar que ocupan las ESE de tipo comunitario y no comunitario. El concepto de ESE, que sirve de partida, se ha construido combinando diversas perspectivas de la sociología económica. Esta aproximación permite contemplar la variedad de formas que pueden adoptar las relaciones sociales de endeudamiento.-Muestra de esta variedad es la diferencia entre las ESE de tipo Gemeinschaft y Gesellschaft, que constituyen las formas típicas ideales que orientan la investigación.

A lo largo del artículo, se ha visto cómo estos dos tipos ideales de ESE se solapan entre sí, produciéndose tránsitos entre lo formal y lo informal, siendo 
utilizados por los diversos actores de modo simultáneo o sucesivo. Además, las estructuras comunitarias pueden constituir, unas veces, una forma tradicional de apoyo mutuo e intercambio social ante la ausencia o la distancia (espacial, económica, cultural) de un sistema financiero formal, y otras, pueden constituir una opción disponible o una vía de refugio ante las crisis crediticias.

La investigación nos permite aproximarnos al papel que desempeñan las estructuras bancarias y las comunitarias en el abanico de oportunidades en el que piensan las personas cuando necesitan una gran cantidad de dinero. Y, sobre todo, nos permite descubrir algunas de las características internas del universo de posiciones de proximidad comunitaria, de la familia o de fuera de la familia, que se adoptan como referencia, así como los contrastes entre países según niveles de desarrollo. Estas estructuras de proximidad forman parte de la economía informal, estadísticamente invisible, que tanto peso tienen en los países más pobres y que constituye uno de los temas sobre los que ha mostrado interés la sociología económica (Portes, 2013; Hoss y Herranz, 1995).

La encuesta ISSP 2001 nos ofrece una representación de la ESE a partir de la mirada y de las respuestas de los actores directamente implicados en la relación de endeudamiento. Además, el modo en que la población «define socialmente las ESE» encuentra una razonable correspondencia con las oportunidades que ofrece el sistema crediticio y las características de los círculos familiares de cada país. El análisis de la estructura social, de la situación económica y del orden institucional con el que se cierra el análisis contribuye a explicar el comportamiento observado en los países y, a su vez, permite poner de relieve la diversidad de formas económicas y de trayectorias institucionales de los países de cada uno de los conglomerados.

Aunque la información empleada es del año 2001, por el momento la encuesta no ha sido replicada, y el análisis realizado, contextualizado históricamente, puede constituir un valor añadido en comparación con los resultados que sobre las ESE comunitarias, se podrían obtener a partir de encuestas más actuales, como es el caso de la Global Findex Data del Banco Mundial.

La agrupación presentada se construyó sobre una base limitada de países, dado que, en la encuesta ISSP 2001, quedan amplias zonas geográficas sin cobertura. Aunque están presentes países de todos los continentes, es evidente la limitada representación de un gran número de territorios de África, Oriente Próximo, Asia y Sudamérica. En este sentido, la inclusión de estas áreas podría alterar la solución mostrada, más aún teniendo en cuenta que las zonas excluidas del estudio mayoritariamente corresponden a países de menor nivel de desarrollo. Observando los resultados y las pautas que se desprenden de este estudio, es razonable esperar que estos países se «orientarán» con más frecuencia a las estructuras comunitarias de proximidad, familiares y no familiares, y, en ellos, presumiblemente, se incrementarán de un modo notable y a medida que nos situemos en el cuarto mundo, aquellas personas excluidas tanto de las redes bancarias como de las redes comunitarias.

Los resultados que se presentan tienen que ver con las redes «imaginadas» y con unas orientaciones que encuentran su anclaje en una estructura social de 
endeudamiento y de la que dan cuenta a modo de un boceto borroso. El trabajo nos ha permitido presentar algunas ideas y proposiciones que pueden generar nuevas hipótesis e investigaciones de interés en el ámbito de los espacios financieros formales e informales, así como de las formas que pueden adoptar «las estructuras sociales del endeudamiento» en el contexto de las dinámicas del desarrollo económico.

\section{Referencias bibliográficas}

Adams, Dale y Canavesi Shonero, Marie Lissette (1989). «Rotating Savings and Credit Associations in Bolivia». Savings and Developments, 13, 219-236.

ANDRÉu ABELÁ, Jaime (2011). «El análisis multinivel: Una revisión actualizada en el ámbito sociológico». Metodología de Encuestas, 13, 161-176.

Aryeetey, Ernest (2001). «Informal Finance for Private Sector Development in Sub-Saharab Africa». Journal of Microfinance, 7 (1), 13-38.

Attias-Donfut, Claudin (2000). «Rapports de generations: Transfers intrafamiliaux et dynamique macro sociale». Revue Française de Sociologie [en línea], 41 (4), 643684 . $<$ http://dx.doi.org/10.2307/3322701>.

Bauman, Zigmunt (2010). Vida de consumo. México: FCE.

Banco Mundial (2001). Informe sobre el desarrollo Mundial 2000/2001: Lucha contra la pobreza. Madrid: Ediciones Mundi-Prensa.

BiggarT, Nicole Woolsey (2001). «Banking on Each Other: The Situation Logic of Rotating Saving and Credit Association». Advance in Qualitative Organization Research, 3, 129-153.

Blic, Damien de y Lazarus, Jeanne (2007). Sociologie de l'argent. París: La Découverte.

Bourdieu, Pierre (2000). La estructura social de la economía. Barcelona: Anagrama.

Bourdieu, Pierre; Boltanski, Luc y Chambopderon, Jean Claude (1964). La banque et sa clientèle: Eléments d'une sociologie du crédit. Etude realisée sous la direction de Pierre Bourdieu par Luc Bolstnaski et Jean-Claude Chamboderon. París: Centre de Sociologie Européenne. Manuscrito no publicado.

Carruthers, Bruce G. (2015). «Financialization and the institutional foundation of the new capitalism». Socio-Economic Review [en línea], 13 (2), 379-398. $<$ http://dx.doi.org/10.1093/ser/mwv008>.

Carruthers, Bruce G. y Ariovich, Laura (2010). Money and Credit: A Sociological Approach. Cambridge: Polity Press.

Chen, Greg y Rutherford, Stuart (2013). Crisis de microcrédito evitada: El caso de Bangladesh, 87, 1-19. CGAP.

Collins, Daryl; Morduch, Jonathan; Rutherford, Stuart y Ruthren, Orlanda (2009). Portfolios of the Poor. Princeton: Princeton University Press.

Crouch, Colin (2011). The Strange non-death of Neo-liberalism. Cambridge: Polity Press.

Durkheim, Émile (1893). La división del trabajo social. Madrid: Akal, 1982.

Esping-ANDERSEn, Gøsta (2000). Fundamentos sociales de las economías postindustriales. Barcelona: Ariel.

Fligstein, Neil (2001). The Architecture of the Markets. Princeton: Princeton University Press. 
Fligstein, Neil y Goldstein, Adam (2015). «The emergence of a finance culture in American Hoseholds, 1987-2007». Socio-Economic Review [en línea], 13 (3), 575-601. <http://dx.doi.org/10.1093/ser/mwu035>.

Granovetter, Mark (1985). «Economic Action, Social Structure and Embeddedness». American Journal of Sociology [en línea], 91 (3), 481-510. <http://dx.doi.org/10.1086/228311>.

- (2003). «La fuerza de los lazos débiles: Revisión de la teoría retícular». En: ReQueNA Santos, Félix (comp.). Análisis de redes sociales. Madrid: CIS.

Guillén, Mauro F. y Tschoegl, Adrian. E. (2000). «The internationalization of retail banking: The case of the Spanish Banks in Latin America». Transnacional Corporation, 9 (3).

Herranz, Roberto (2008). «Georg Simmel y la Sociologia Económica: El mercado, las formas sociales y el análisis estratégico». Papers [en línea], 87, 269-286. <http://dx.doi.org/10.5565/rev/papers/v87n0.806>.

Hoss, Dietrich y Herranz, Roberto (1995). «The Division of Labour between Centre and Periphery in Industrial Networks: The case of Galicia». En: Liтtek, Wolfgang y Charles, Tony (eds.). The New Division of Labour. Emerging Forms of Work Organisation in International Perspective. Nueva York: Walter de Gruyter. <http://dx.doi.org/10.1515/9783110890747.437>.

IAcovou, Maria y Skew, Alexandra J. (2010). "Household Structure in the EU». En: Atkinson, Anthony B. y Marlier, Eric (eds.). Income and living conditions in Europe [en línea]. Luxemburgo: Publications Office of the European Union. $<$ http://dx.doi.org/10.2785/53320>.

Ingham, Geoffrey (2010). Capitalismo. Madrid: Alianza Editorial.

ISSP Research Group (2003). International Social Survey Programme: Social Relations and Support Systems / Social Networks II - ISSP 2001. GESIS Data Archive, Cologne. ZA3680 Data file Version 1.0.0. <http://dx.doi.org/10.4232/1.3680>.

Karim, Lamia (2011). Microfinances and its discontents: Women in Debt in Bangladesh. Londres: University of Minnesota Press. <http://dx.doi.org/10.5749/minnesota/9780816670949.001.0001>.

KIng, Lawrence P. y SzeléNyI, Ivan (2005). «Pos-Comunism Economic System». En: Smelser, Neil. J. y Sweberg, Richard. The Handbook of Economic Sociology [en línea]. Nueva York y Princeton: University Press. <http://dx.doi.org/10.1515/9781400835584.205>.

Knorr Cetina, Karin y Preda, Alex (2012). The Sociology of Finance [en línea]. Oxford: Oxford University Press. <http://dx.doi.org/10.1093/oxfordhb/9780199590162.001.0001>.

Light, Ivan H. (1972). Ethnic Enterprise in America, Berkeley y Los Angeles. Berkeley: University of California Press.

- (2005). «The Ethnic Economy». En: Swedberg, Richard y Smelser, Neil (eds.). The Handbook of Economic Sociology [en línea]. Princeton: Princeton University Press. <http://dx.doi.org/10.1515/9781400835584.650>.

Mader, Philipe (2015). The Political Economy of Microfinance: Financializing Poverty. Nueva York: Palgrave Macmillan.

Merton, Robert (1964). Teoría y estructura sociales. México: FCE.

Nee, Victor e Ingram, Paul (1998). «Embeddedness and Beyond: Institutions, Exchange and Social Structure». En: Brinton, Mary y NeE, Victor. The New Institutionalism in Sociology. Nueva York: Russel Sage Foundations. 
Philippon, Thomas y Reshef, Ariell (2013). «An International Look at the Growth of Modern Finance». Journal of Economic Perspectives [en línea], 27 (2), 73-96. <http://dx.doi.org/10.2469/dig.v43.n4.47>.

Portes, Alejandro (2013). Sociología económica: Una investigación sistemática. Madrid: Centro de Investigaciones Sociológicas.

Puntscher, Sibylle; Hauser, Christoph; Walde, Janette y Tappeiner, Gottfried (2016). "Measuring Social Capital with Aggregated Indicators: A Case of Ecological Fallacy?». Social Indicators Research [en línea], 125, 431-449. <http://dx.doi.org/10.1007/s11205-014-0843-z>.

Requena Santos, Félix (2011). Las redes de apoyo social. Madrid: Civitas.

Rona-Tas, Akos y Guseva, Alya (2014). Plastic Money: Constructing Markets for Credit Card in Eight Postcommunists Countries [en línea]. Stanford: Stanford University Press. <http://dx.doi.org/10.11126/stanford/9780804768573.003.0005>.

SAnd-Zantman, Alain (2005). "O Brasil de Lula: É posible a utopía reformista na globalización financiera». Revista Galega de Economía [en línea], 14 (1-2), 441-467.

Sanyal, Paromita (2014). Credit to Capabilities: A Sociological Study of Microcredit Groups in India [en línea]. Cambridge: Cambridge University Press. <http://dx.doi.org/10.1017/cbo9781139939461>.

Sen, Amartya (2000). Desarrollo y libertad. Barcelona: Planeta.

Simmel, Georg (1900). Filosofía del dinero. Madrid: Capitán Swing, 2013.

Snijders, Tom A.B. y Bosker, Roel J. (1999). An introduction to basic and advanced multilevel modelling. Londres: SAGE Publications.

Stiglitz, Joseph E. (2002). El malestar de la globalización. Madrid: Taurus.

Sullivan, Teresa A.; Warren, Elizabeth y Westbrook, Jay Lawrence (2000). The Fragile Middle Class: Americans in Debt. New Haven y Londres: Yale University Press.

Swedberg, Richard (2010). «The Economic Sociologies of Pierre Bourdieu». Cultural Sociology [en línea], 5 (1), 1-18. <http://dx.doi.org/10.1177/1749975510389712>.

Swedberg, Richard y Smelser, Neil (2005). The Handbook of Economic Sociology. Princeton: Princeton University Press.

Tönnies, Ferdinand (1887). Comunidad y asociación. Barcelona: Península, 1979.

TsaI, Kellee (2004). «Imperfect Substitutes: The Local Political Economy of Informal Financial and Microfinance in Rural China and India». World Development [en línea], 32 (9), 1487-1507. <http://dx.doi.org/10.1016/j.worlddev.2004.06.001>.

Weber, Max (1922). Economía y sociedad. México: FCE, 1964.

World BANK (2014). Global Findex Database. 